\title{
Thermodynamic and economic analysis of the integration of Organic Rankine Cycle and Multi-Effect Distillation in waste-heat recovery applications
}

\author{
A. Baccioli, M. Antonelli, U. Desideri, A. Grossi. \\ Department of Energy, System, Territory and Construction \\ University of Pisa, Pisa, Italy \\ e-mail: andrea.baccioli@unipi.it
}

\begin{abstract}
The possibility of coupling a small-scale Multi-Effect Distillation system for seawater desalination with a waste heat recovery Organic Rankine Cycle in a cogenerative system has been studied from the thermodynamic and economic point of view. Two different configurations have been analysed: a hybrid serial-cascade configuration and a cascade configuration. The heat source was a generic waste heat flow at medium temperature, which heated up diathermic oil, operating as heat transfer fluid. The oil was supposed to be Therminol VP1, heated by the heat source at $200^{\circ} \mathrm{C}$. Four different sizes were considered for the MultiEffect Distillation, from 500 up to $2000 \mathrm{~m}^{3} /$ day. The thermodynamic analysis highlighted that the second law efficiency decreased with the desalination unit size for the hybrid configuration, while presented a maximum value in the Multi-Effect Distillation size range $500-2000 \mathrm{~m}^{3}$ for the cascade configuration. For the serial-hybrid configuration, the second law efficiency decreased from $43.1 \%$ to $15.5 \%$ when passing from a Multi-Effect Distillation size of 500 $\mathrm{m}^{3} /$ day to a size of $2000 \mathrm{~m}^{3} /$ day, while for the cascade the values were largely lower, but with a reduced variation between 26.2 and $21.4 \%$. The economic analysis showed that the hybrid configuration reduced to a serial configuration, due to the high costs of heat exchangers, and this last was largely more profitable respect to the cascade configuration. Moreover, when the size of the Multi-Effect Distillation was smaller, the investment could be convenient also for a
\end{abstract}


water price of $0.8 \$ / \mathrm{m}^{3}$, and the profitability index in some configurations reached 2.4 with this water price. In most of the cases, with a serial configuration, the coupling with an Organic Rankine Cycle increased the investment profit and reduced the payback time, especially with a small size of the desalination plant.

\section{KEYWORDS}

Cogeneration, Organic Rankine Cycle, Multi-Effect Distillation, Waste Heat Recovery, Thermo-economic Analysis.

\section{INTRODUCTION}

Desalination is an increasing need for many localities of the world due to population growth and climate change. The large energy consumption required by processes has led to consider renewable energies or the recovery of waste heat from industrial to fuel the process.

Several desalination processes have been developed and can be divided in two main groups: mechanical separation, where water is passed through a membrane without phase change or thermal distillation, where distillate water is obtained through evaporation [1].

Thermal distillation normally provides higher energy consumption than mechanical separation [2], but due to the low temperature required, can exploit the heat from a thermal process, as shown as an example in [3], where a thermal vapour compression MED is fed by the steam from a Rankine cycle. Other authors considered the integration of the MED in poly-generative context [4] and evaluated the performance of various thermal desalination processes integrated with solar systems [5]. Among the thermal processes, Multi-Effect Distillation (MED) requires less energy than Multi-Stage Flash (MSF), as reported in various research paper, such as [6], where a comparison between MED and MSF was evaluated, both in design and in operation, and [7], where the profitability of various desalination systems was compared [7]. The comparison between thermal desalination processes and reverse osmosis (RO) was conducted 
in [8]: thermal desalination processes are characterized by a larger energy input than that of RO. However in the case of heat availability from renewable heat source or waste heat recovery (WHR) context, thermal desalination represent a viable way of producing distillate water. Waste heat is normally produced by engines or processes as a by-product. Recovering this heat can increase the efficiency of the system or, in the case of thermal desalination system can provide the heat necessary to drive the desalination unit. When coupling the thermal distillation system with renewable energy or with waste energy streams, it is important to notice that MSF stages require a precise control of pressure and temperature to keep the pressure constant between the various stages [9], making these systems particularly suitable for large applications. The average size of MED systems is much lower than that of MSF, as reported in [10], where the technical features of various desalination plants are reported and [11] where an overview of various desalination system is proposed.

Thermal processes, such as MED and MSF can be combined with power generation plants: the most common practice is to connect MED or MSF plants to steam or combined cycles. As an example, Darwish et al. in [12] reported various possibilities of coupling thermal desalination systems to combined cycle. Almutairi et al. in [13] reported an interesting energetic and exergetic analysis of a Vapor-Compression MED (VC-MED) where the steam for the ejector was provided by a combined cycle, Hanafi et al. in [14] and Maghsoudi et al. in [15] reported also a techno-economic analysis of a VC-MED, highlighting the profitability of the proposed systems.. In all these cases, very large desalination plants are considered. Various configuration of smaller cogenerative and poly-generative systems, which includes a desalination plant have also been investigated in the literature: Rubio et al. [16] modelled a RO desalination system driven by an Internal Combustion Engine (ICE) for a tourist complex: an absorption chiller recovers the exhaust gas of the engine to provide the refrigeration of the buildings; Serra et al. in [17] compared three different example of poly-generation systems, including an industrial 
process, a district heating and a saltwater desalination process with MED, demonstrating the increase of the energy efficiency. Maheswari et al in [18] carried an experimental test to feed a single evaporative desalination chamber with the waste heat from diesel engine.

In general, it is demonstrated that desalination processes included in cogenerative or polygenerative systems can increase the global efficiency, reduce the distillation costs and the water price $[4,17,18]$. A very interesting cogenerative application is the coupling of desalination thermal processes, especially MED, with Organic Rankine Cycle (ORC): the integration of Organic Rankine Cycles with desalination process has been widely investigated with Reverse Osmosis (RO) [19], while few authors focused on the combination of ORC with thermal desalination process. Araghi et al. in [20], proposed an ORC system to recover heat from a vapour stream to produce electric power and distillate water, preheating the seawater with the heat discharged by the ORC condenser. Various mixtures of butane and propane were used as working fluid. Sharaf et al. in [21] carried an exergo-economic analysis on a solar MED system, comparing two different solutions: direct solar heating of the first stage of the MED with the vapour produced by the solar field, and a cogenerative solar ORC, where the condensing heat of the ORC provided the necessary heat to the MED. Results indicated that the capital cost of the poly-generative solution negatively affects the economic performance of the system due to the high area and cost of the solar field: MED plants included in a poly-generative scheme are not economic when solar radiation is the heat source. In a further paper [3] a solar ORC with toluene was used to drive a multi effect distillation vapour compression system: the power delivered by the ORC module was used to drive the steam compressor and the heat reject by the condenser preheated seawater. Maraver et al. in [4] proposed a system to produce energy and desalted water through a polygenerative high temperature ORC (fuelled by biomass) to produce electricity, heat and desalted water through a MED distillation system. The system demonstrated to be economic and, due to poly-generation it was possible to reduce the price of 
the purified water. In [22], Sharaf et al. compared three different cogeneration schemes to produce desalted water using the combustion of refinery waste gases as heat source. In a first scheme, waste gases were burnt in a boiler to produce steam to feed both a MSF and a MED connected in series; the second scheme is similar to the first, but the flue gas of the boiler was recovered by an ORC to produce electricity; in a third scheme, the waste gas was burned in a gas turbine and flue gas from the turbine is used to feed a MSF plant. The results are obvious: the last scheme minimized the irreversibility and the costs of the system, since the flue gas was burned in a turbine and not in a boiler.

The actual feasibility of the MED-ORC coupling for various water and electricity price as well as the optimal thermodynamic and economic configuration scheme has not still defined in the literature.

In this work a waste heat recovery system with ORC and MED plant to produce electricity and distillate water has been proposed, comparing two different configurations: hybrid serialcascade and cascade configuration. The analysis and the comparison between the two configurations was carried out through thermodynamic and economic assessments. In hybrid configuration (serial-cascade), the hot stream firstly evaporated the organic fluid and then provided part of the heat to the MED. The remaining part of the heat necessary to the water evaporation was provided in a preheater heated by the working fluid. The cascade configuration is a configuration where the heat rejected by the topping cycle is transferred to a bottoming cycle or process. In this configuration, the hot fluid provided the heat to the ORC evaporator: the heat necessary to the MED is transferred by the condensation of the organic fluid. The aim of the work is to define the most viable cogenerative architecture from the thermodynamic and economic point of view for MED-ORC coupling in medium temperature WHR context, from those processes, such as oil plants, which can provide heat at medium temperature (about $200^{\circ} \mathrm{C}$ ). The behaviour of cogenerative systems, as a function of the architecture configuration 
has been described in the literature for those systems whose output is electricity and heat [23].

In the case of desalination processes, the low exergy contribution and the high cost of the thermal desalination unit may lead to different results and an analysis on the most performant configuration is still lacking. Respect to other previous published papers on the topic, where a single architecture is analysed, the paper analyses a mid-temperature WHR and defines, the most efficient and profitable architecture for various MED sizes as a function of water and electricity price.

\section{CASE STUDY}

The system investigated in this study is a Waste Heat Recovery with an ORC and a MED distillation plant. Two different system layouts have been defined: hybrid serial-cascade (fig. 1A) and cascade configuration (fig. 1B). In the hybrid serial-cascade configuration, the heat source heated up the diathermic oil (heat transfer fluid) in a heat exchanger. After heating, the oil, entered the ORC evaporator to evaporate the working fluid. After the evaporator, the HTF was transferred to the first stage of the MED to provide the heat necessary to the process. In the ORC module, the dry fluid after the evaporation was expanded in the turbine and then, the superheated vapour, was sent to the MED to preheat the water. The remaining part of the condensing heat was rejected in an external condenser, cooled by seawater. The diathermic oil, left the MED evaporator and flowed back to the heat exchanger to be heated by the heat source. In the cascade configuration (fig. 1B), instead, the hot diathermic oil, was sent to the ORC evaporator, to evaporate the working fluid. After the ORC evaporator the diathermic oil was sent back to the heat exchanger to be reheated. The working fluid after evaporation flowed in the ORC turbine and then was directly condensed in the MED first stage evaporator, where provided the heat necessary to vaporize part of the seawater. A further seawater condenser should be eventually adopted to complete the working fluid condensation. 
The working fluid of the ORC was supposed to be n-Pentane, due to the good agreement between the fluid critical temperature and the heat source temperature, and to the high vapour density that reduces the size of evaporator, turbine and condenser [24].

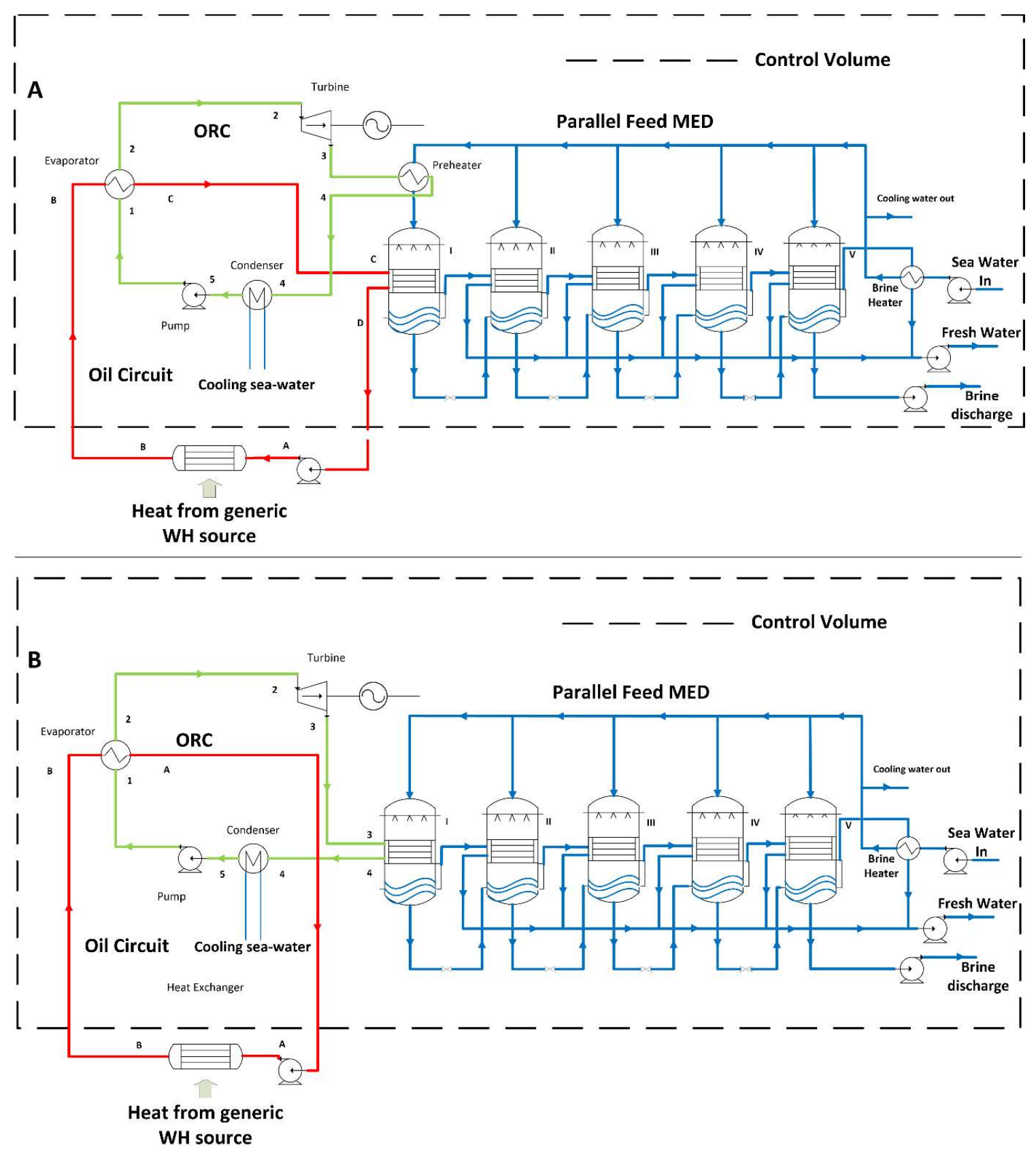

Figure 1. -Scheme of the two configurations: hybrid serial-cascade (A) and cascade (B). 
In this study, the heat source was not modelled, since different heating streams can fuel the proposed system. For this reason, in this study, the control volume considered does not include the heat transfer process with the heat source, as from fig. 1a and b. The diathermic oil was Therminol VP-1, with a hot temperature of $200^{\circ} \mathrm{C}$ and with a mass flow rate of about $61.6 \mathrm{~kg} / \mathrm{s}$. If the temperature of the oil could be reduced up to the death state $\left(20^{\circ} \mathrm{C}\right.$ and $\left.1.01 \mathrm{bar}\right)$, it would provide to the system an amount of thermal power equal to $20 \mathrm{MW}$, according to eq.1:

$\dot{Q}_{a v}=\dot{m}_{o i l} \cdot C_{p} \cdot\left(T_{B}-T_{0}\right)$

where $T_{0}$ is the death state temperature, and $T_{B}$ (fig. 1) is the temperature of the oil at the ORC evaporator inlet.

The MED desalination system was composed of 5 distillation stages in parallel configuration, with a top brine temperature of $70^{\circ} \mathrm{C}$. In this work various MED sizes were considered, but the number of stages in all the cases was equal to 5, as well as the pressure and temperature of each stage. The difference between the various configurations is the different mass flow rate of treated water. The salinity of seawater was considered constant and equal to $35000 \mathrm{ppm}$.

\section{MATERIAL AND METHODS}

The system was completely modelled in Aspen HYSYS, including the MED. Aspen HYSYS is a reference commercial software for the simulation of industrial process, involving also chemical reactions, physical separations, distillation and so on [25]. The main assumption considered in the model are reported below:

- Steady-state operation;

- Constant salinity of the seawater;

- Perfect distillation (concentration of salt equal to zero in the desalted water);

- Constant pressure drops in the heat exchangers;

- No subcooling in the ORC; 
- Constant pumps (0.7) and turbine efficiencies (0.85);

- No heat exchange with the environment (adiabatic process) for all the components of the system;

\subsection{Multi-Effect Distillation model}

The hypothesis in the simulation of the MED are common to other literature papers reporting a MED simulation with Aspen HYSYS [26].

In the MED model the Electrolyte NRTL equation of state (EoS) was adopted to simulate the MED, as suggested in the software reference guide [25] for distillation processes. The Electrolyte-NRTL activity coefficient model is a versatile model for the calculation of activity coefficients. Using binary and pair parameters, the model can represent aqueous electrolyte systems as well as mixed solvent electrolyte systems over the entire range of electrolyte concentrations. This model can calculate activity coefficients for ionic species and molecular species in aqueous electrolyte systems as well as in mixed solvent electrolyte systems [25]. This equation, despite the capability of simulating aqueous solution with more than one solvent provides good results also in the case of $\mathrm{NaCl}-$ Water mixtures [27] and was adopted in the simulation of desalination systems [28]

The main equations for each stage of the MED are reported below:

For all the heat exchangers of the MED, (evaporator of each stage, brine heater and eventual preheater), the enthalpy balance was evaluated as:

$\dot{m}_{h o} \cdot \Delta h_{\text {hot }}=\dot{m}_{\text {cold }} \cdot \Delta h_{\text {cold }}$

where $\dot{m}_{h o t}$ and $\Delta h_{h o t}$ are respectively the mass flow and the enthalpy drop of the hot fluid and $\dot{m}_{\text {cold }}$ and $\Delta h_{\text {cold }}$ are respectively the mass flow and the enthalpy rise of the cold fluid in the heat exchanger. 
Due to the presence of the salt the boiling temperature of the water at a fixed temperature needed a correction respect to the boiling point of the pure water. This correction is known as boiling point elevation and is considered in the Electrolyte-NRTL EoS.

In the first stage of the MED the main equations were:

$\dot{m}_{h o t} \cdot \Delta h_{h o t}=\dot{m}_{1, s w} \Delta h_{s}+\dot{m}_{1, l} \Delta h_{l}$

Where $\dot{m}_{1, s w}$ is the seawater flowing in the first MED stage, $\Delta h_{s}$ is the specific enthalpy necessary to increase the temperature of the water from the brine heater temperature to the top brine temperature, $\dot{m}_{1, l}$ is the mass flow of water that vaporizes and $\Delta h_{l}$ is the enthalpy of vaporization.

Particularly, in the first stage, the heat provided to the MED in the serial configuration was the sum of the heat provided in the preheater by the ORC working fluid and of the heat provided in the evaporator by the oil (subscripts refer to fig. 1A):

$\dot{Q}=\dot{m}_{R 601} \cdot\left(h_{3}-h_{4}\right)+\dot{m}_{o i l} \cdot\left(h_{C}-h_{A}\right)$

where $\dot{m}_{R 601}$ is the mass flow rate of the organic fluid. In the cascade configuration, instead the heat provided to the MED was transferred during the condensation process of the ORC (subscripts refer to fig. 1B):

$\dot{Q}=\dot{m}_{R 601} \cdot\left(h_{3}-h_{4}\right)$

The mass flow of brine in the first stage was evaluated as:

$\dot{m}_{I, b}=\dot{m}_{I, s w}-\dot{m}_{I, l}$

and the salinity of the brine was:

$S_{I}=\frac{\dot{m}_{I, S W} \cdot S_{S W}}{\dot{m}_{I, b}}$

where $S_{s w}$ is the salinity of seawater.

In the generic $\mathrm{i}^{\text {th }}$ effect of the MED, the energy balance was:

$\dot{m}_{i, l} \cdot \Delta h_{i, l}+\dot{m}_{i, s w} \Delta h_{s}=\dot{m}_{(i-1), l} \cdot \Delta h_{(i-1), l}+\dot{m}_{(i-1), b} \cdot \Delta+\dot{m}_{i, b} \cdot \Delta h_{i}$ 
where the first term represents the enthalpy necessary to increase the temperature and evaporate the salt water entering in the stage, the term $\dot{m}_{(i-1), l} \cdot \Delta h_{(i-1), l}+\dot{m}_{(i-1), b} \cdot \Delta h_{i, s}$ represents the enthalpy of condensation and cooling of the desalted water flowing from the previous stage and $\dot{m}_{i, b} \cdot \Delta h_{i}$ is the contribution of the brine flash.

The model of the MED simulated in Aspen HYSYS has been compared with data presented in [29] in terms of performance ratio, which is defined as:

P.R. $=\frac{\dot{m}_{d}}{\dot{m}_{s}}=\frac{\dot{m}_{d} \Delta h}{\dot{Q}}$

where $\dot{m}_{d}$ is the distillate mass flow rate, $\dot{m}_{s}$ is the mass flow rate of a hypothetical steam flux condensing at the temperature of $70^{\circ} \mathrm{C}$ and used to evaporate the water in the first MED stage, $\Delta h$ is the latent heat of water at $70^{\circ} \mathrm{C}$ and $\dot{Q}$ is the thermal power requested by the process. The performance ratio of the simulated system resulted to be 4.46 . Interpolating the data presented in [29], for 5 MED parallel stages and a salinity of $35000 \mathrm{ppm}$, the performance ratio resulted to be 4.44 with a relative difference between the model and the literature data of $0.5 \%$. This difference was retained to be acceptably low for the purposes of the present study.

Table 1. Main MED parameters

\begin{tabular}{lcc}
\hline Parameter & Unit & Value \\
\hline Number of stages & - & 5 \\
\hline Performance Ratio & - & 4.46 \\
Conversion ratio & {$[\%]$} & 49.7 \\
First stage temperature & {$\left[{ }^{\circ} \mathrm{C}\right]$} & 70 \\
Second stage temperature & {$\left[{ }^{\circ} \mathrm{C}\right]$} & 62.5 \\
Third stage temperature & {$\left[{ }^{\circ} \mathrm{C}\right]$} & 55 \\
Fourth stage temperature & {$\left[{ }^{\circ} \mathrm{C}\right]$} & 47.5
\end{tabular}


Fifth stage temperature

Specific heat consumption

Specific electric consumption $\left[\mathrm{kWh} / \mathrm{m}^{3}\right]$
40

146.9

0.2

\subsection{Diathermic oil circuit}

For the modelling of the diathermic oil, the UNIQUAC EoS was adopted. Despite the complexity of this equation which is addressed to solutions of two different compounds, in the temperature range between $200^{\circ} \mathrm{C}$ and $80^{\circ} \mathrm{C}$, with this EoS, the maximum error of the model in the evaluation of specific heat and density of the fluid with respect to the fluid datasheet [30] was of $1.3 \%$ and $0.2 \%$ respectively. Due to the small difference between the simulated and the declared data, the UNIQUAC EoS was retained suitable

for the simulation of Therminol VP1. The heat transferred from the diathermic oil to the ORC, in the case of serial configuration was evaluated as:

$\dot{Q}_{O R C}=\dot{m}_{o i l}\left(h_{B}-h_{C}\right)$

Always in this configuration, the heat transferred by the oil to the MED was computed as:

$\dot{Q}_{M E D}=\dot{m}_{o i l}\left(h_{C}-h_{A}\right)$

where $\dot{m}_{o i l}$ is the mass flow rate of diathermic oil, $\mathrm{h}$ is the specific enthalpy and subscripts refers to fig. $1 \mathrm{~A}$.

In the case of serial configuration, the heat transferred to the ORC was:

$\dot{Q}_{\text {ORC }}=\dot{m}_{\text {oil }}\left(h_{B}-h_{A}\right)$

where subscripts refers to fig. 1B.

\subsection{Organic Rankine Cycle}

Regarding the ORC modelling, the Refprop EoS was considered. This model is recognized as one of the most accurate model in the evaluation of the properties of the pure fluids. The heat transferred to the ORC evaporator was computed as (from fig. $1 \mathrm{~A}$ and $\mathrm{B}$ ): 
$\dot{Q}=\dot{m}_{R 601}\left(h_{2}-h_{1}\right)$

where $\dot{m}_{R 601 a}$ is the mass flow rate of n-pentane.

The power output from the turbine was computed as:

$\dot{W}_{t}=\dot{m}_{R 6} \cdot \Delta h_{i s} \cdot \eta_{i s} \cdot \eta_{e l}$

where $\Delta h_{i s}$ is the isentropic enthalpy drop, $\eta_{i s}$ is the isentropic efficiency and $\eta_{e l}$ is the electric efficiency. An isentropic efficiency of 0.85 , and an electric efficiency of 0.95 were considered. The heat rejected to the condenser in the case of serial configuration was evaluated as:

$\dot{Q}=\dot{m}_{R 601}\left(h_{4}-h_{5}\right)$

In the case of cascade configuration was evaluated as: $Q=\dot{m}_{R 601}\left(h_{3}-h_{4}\right)+\dot{m}_{R 601}\left(h_{4}-h_{5}\right)$

The pump power absorption was computed as

$\dot{W}_{f . p .}=\frac{\dot{V}_{R 601}\left(P_{1}-P_{5}\right)}{\rho_{5} \cdot \eta_{f . p .} \cdot \eta_{e l}}$

where $\dot{V}_{R 601}$ is the volume flow rate of the working fluid, $P_{1}-P_{5}$ is the pressure difference, $\rho_{5}$ is the density of the fluid, $\eta_{f . p .}$ is the isentropic efficiency of the pump (considered constant and equal to 0.7 ) and $\eta_{e l}$ is the electric efficiency of the pump motor (considered equal to 0.95). The efficiency of the devices was considered constant and consistent with the literature. The ORC turbine power partly supplied the MED and the ORC feed pump electric requirement, while the remaining part was sent to the grid or to the process upstream of the system.

The net power output of the system was computed as:

$\dot{W}_{N E T}=\dot{W}_{t}-\dot{W}_{f . p .}-\sum_{n} \dot{W}_{p_{n}, M E D}$

where the sum is extended to all the pumps of the MED.

The electric efficiency of the cycle was computed as:

$\eta=\frac{\dot{W}_{N E T}}{\dot{Q}_{\text {exch }}}$

where $\dot{Q}_{\text {exch }}$ is the heat exchanged with the diathermic oil. 


\subsection{Second law analysis}

To evaluate the performance of the WHR ORC-MED a second law analysis was carried out. The death state was assumed to be the environment at $20^{\circ} \mathrm{C}, 101325 \mathrm{~Pa}$ and with an infinite dilution of salt.

Mixing of salt in water is an irreversible process and therefore the entropy of the mixture is larger than the entropy of a pure component. The entropy of a component of a mixture per unit mole in a solution at a generic temperature and pressure is [31]:

$\hat{s}_{i}=\hat{s}_{i, p u r e}(T, P)-R \cdot \ln \left(x_{i}\right)$

where $\hat{s}_{i, p u r e}(T, P)$ is the molar entropy of the component as a function of the temperature and pressure, $R$ is the universal gas constant and $x_{i}$ is the molar fraction of the $\mathrm{i}^{\text {th }}$ component of the mixture.

The molar entropy of the water-salt mixture is therefore:

$$
\begin{aligned}
& \hat{s}=x_{s} \cdot \hat{s}_{s}+x_{w} \cdot \hat{s}_{w}=x_{s}\left[\hat{s}_{s, \text { pure }}(T, P)-R \ln \left(x_{s}\right)\right]+x_{w}\left[\hat{s}_{w, p u r e}(T, P)-R \ln \left(x_{w}\right)\right] \\
& =x_{s} \cdot \hat{s}_{s, p u r e}(T, P)+x_{w} \cdot \hat{s}_{w, p u r e}(T, P)-R\left(x_{s} \ln x_{s}+x_{w} \ln x_{w}\right)
\end{aligned}
$$

The specific mass entropy is therefore obtained dividing by the molar mass of the solution:

$S=\frac{x_{S} \cdot \hat{s}_{s, p u r e}(T, P)+x_{w} \cdot \hat{s}_{w, p u r e}(T, P)-R\left(x_{S} \ln x_{S}+x_{w} \ln x_{w}\right)}{M_{m}}$

The exergy flow rate is therefore

$\dot{E} x=\dot{m} \cdot\left[\left(h-h_{0}\right)-T_{0}\left(s-s_{0}\right)\right]$

The minimum work necessary to distillate seawater is therefore the sum of all the outputs (distillate water and brine) minus the seawater input:

$\dot{W}_{\text {min }}=\dot{E} x_{d}+\dot{E} x_{b}-\dot{E} x_{s . w}$ 
It is worth to notice that the physical exergy of these three terms was zero: in fact, the seawater temperature and pressure were the same of the death state, while the physical exergy of both distillate water and brine was not recovered, representing an exergy loss.

The second law efficiency of the system can be expressed as:

$\eta^{I I}=\frac{\dot{W}_{N E T}+\dot{W}_{\min }}{\dot{E} x_{\text {oil }}}$

where $\dot{E} x_{o i l}$ is the exergy of the oil flow rate at the inlet of the ORC evaporator. This formula considers only the oil exergy since the heat source is not modeled in this work. The exergy of the oil recirculating back to the heat exchanger was not computed in this formulation: in fact, this exergy does not provide any benefic effect to the system in the case of a WHR and can be considered a loss. In fact, it is possible to assume that the lower the oil temperature, the lower the discharge temperature of the heat source, allowing the system to achieve a high recovery efficiency. This approach was also followed in a previous published paper [24].

\subsection{Economic Analysis}

For the economic analysis, the cost of the various components has been evaluated. The average direct cost of the MED was evaluated through a power law relation to scale the size of the plant:

$C_{M E D}=C_{M E D, 0} \cdot\left(\frac{V_{M E D}}{V_{M E D, 0}}\right)^{n}$

where $C_{M E D, 0}$ is the cost of the MED equal to $4 \times 10^{7} \$$ for a daily capacity $\left(V_{M E D, 0}\right)$ of $27000 \mathrm{~m}^{3}$ [29]. The value of the exponent $n$ was evaluated from the results presented in [21] and set equal to 0.68 . No correction on the number of stages was applied due to the lack of literature data: it is worth to notice however that the costs evaluated in this paper can be considered conservative, since available data refer to plants with a larger number of stages. The direct cost of the four sizes analysed in this paper are reported in table 2 . 
Table 2. Direct capital cost of the four sizes of the MED

\begin{tabular}{lcc}
\hline MED Size $\left[\mathrm{m}^{3} /\right.$ day $]$ & Direct Capital Cost $[\$]$ & Specific Cost $\left[\$ / \mathrm{m}^{3} /\right.$ day $]$ \\
\hline 500 & $2.76 \times 10^{6}$ & 5519 \\
1000 & $4.39 \times 10^{6}$ & 4393 \\
1500 & $5.78 \times 10^{6}$ & 3851 \\
2000 & $8.20 \times 10^{6}$ & 3282 \\
\hline
\end{tabular}

The indirect capital cost, including contingency, freight and insurance, construction overhead and owner's costs were evaluated as a percentage of the direct capital cost according to [29]. Operating costs such as annual labour cost, annual chemicals cost and operating and maintenance were considered and evaluated according to [29].

For the ORC, the direct total cost was evaluated as the sum of the costs of the single components. The bare costs of the turbine, of the feed pump and of the heat exchangers were evaluated from the correlation of Turton et al. [32]:

$\log _{10} C_{p 0}=K_{1}+K_{2} \log _{10} A+K_{3}\left(\log _{10} A\right)^{2}$

Where $\mathrm{A}$ is the size parameter of the various devices (exchange area for evaporator, condenser and preheater and mechanical power for turbine and pumps) and the constants $K_{i}$ are a function of the equipment typology (heat exchanger, pump and so on). The heat exchanger surfaces were estimated assuming an overall heat transfer coefficient $U$, obtained from the interpolation of the values reported in [33]. This method has been adopted also in other paper in the literature [34].

The cost of the electric machine was evaluated according to the power law reported in eq. 7 from [35]

$C_{g e n}=1.85 \cdot 10^{6} \cdot\left(\frac{W_{t}}{11800}\right)$ 
To take into account the real cost of the equipment, both the material of construction and the operating pressure of the component was considered, according to [32]. The pressure factors take into account the operating pressure of the equipment. For heat exchangers, turbine and pumps the pressure factor can be expressed as [32]:

$\log _{10} F_{p}=C_{1}+C_{2} \log _{10} P_{g}+C_{3}\left(\log _{10} P_{g}\right)^{2}$

where $P_{g}$ is the equipment operating gauge pressure and the various constants $C_{i}$ are a function of the type of device (similarly to the constants of eq. 22)

The cost of the material depended on the material factor $\left(F_{m}\right)$ which is a function of the type of device and of the type of material adopted and is reported in [32] for the various device. For the heat exchangers exchanging with seawater, stainless steel was considered as construction material, while for the ORC evaporator where corrosion is limited, a more economic carbon steel was considered.

The final cost of the equipment, considering the operating pressure and the material of construction was [32]:

$C_{B M}=C_{p 0} \cdot\left(B_{1}+B_{2} \cdot F_{m} \cdot F_{p}\right)$

Extra costs such as installation, piping, instrumentation and indirect capital costs, including engineering were evaluated from the components final cost $\left(C_{B M}\right)$ according to the relation reported in $[33,32,35]$. In the case of the ORC the extra costs takes into account all the costs of the oil loop, including the ones of the oil heat exchanger, as it is clearly reported in [35]. The total specific costs of the ORC, including the MED preheater, roughly ranged from 3300 to $7000 \$ / \mathrm{kW}$, when passing from a turbine output power of $1600 \mathrm{~kW}$ to few hundred $\mathrm{kW}$ respectively. The resulting ORC costs were of the same order of magnitude of the ones declared in [35]: the higher values found in this paper respect to the literature is justified by the need of employing stainless steel made condensers and preheater. The operating and maintenance costs were evaluated for each device as the $15 \%$ of the cost of the purchased equipment. 
The net present value was evaluated as:

$N P V=-C_{0}+\sum_{n=1}^{L . T .} \frac{\left[P_{w_{n}}+P_{e_{n}}-\left(C_{M E}{ }_{n}+C_{O R C_{n}}\right)\right]}{(1+i)^{n}}$

Where $C_{0}$ is the capital investment, $P_{w_{n}}$ and $P_{e_{n}}$ are the revenues of water and electricity sales (or avoided costs) at the year $\mathrm{n}$ respectively, and $C_{M E D, n}$ and $C_{O R C, n}$ are the annual O\&M costs for the MED and for the ORC at the year $\mathrm{n}$ respectively. $i$ is the discount ratio which in this analysis was considered equal to 0.05 . No tax was considered in this work.

The profitability index was evaluated from the NPV according to eq. 28

$P I=\frac{N P V+C_{0}}{C_{0}}$

The profitability index is the relative increase of the NPV with respect to the capital cost. It quantifies the amount of value created per unit of investment. If the PI assumes values below 1 , the investment is not profitable and the NPV is negative. If the value of PI is 1 the profits equals the cost and therefore means breakeven. If the PI is higher than 1, the investment leads a profit and NPV is positive. The higher is the profitability index the larger is the profit of the investment.

\section{RESULTS}

In this section results from both the thermodynamic and economic optimization are reported for the two configurations analysed.

\subsection{Thermodynamic analysis}

In this sub-section the thermodynamic performance of the two configurations is described for the different MED sizes reported above: results were obtained by maximizing the second law efficiency of the system, using the BOX optimization algorithm. The pinch-points of both the ORC evaporator, MED preheater and MED principal heat exchanger were limited to $5^{\circ} \mathrm{C}$. The evaporating pressure, the superheating grade, the condensing pressure, the preheater outlet temperature (on the organic side, in the case of hybrid configuration) and the HTF evaporator 
outlet temperature were left free of varying in the optimization process. A minimum condensing temperature of $35^{\circ} \mathrm{C}$ was imposed as a constraint to grant the condensing process with seawater, for hybrid configuration.

Results in terms of second law efficiency and net power output are reported in fig. 2 for the three sizes of the MED and the two architectures.
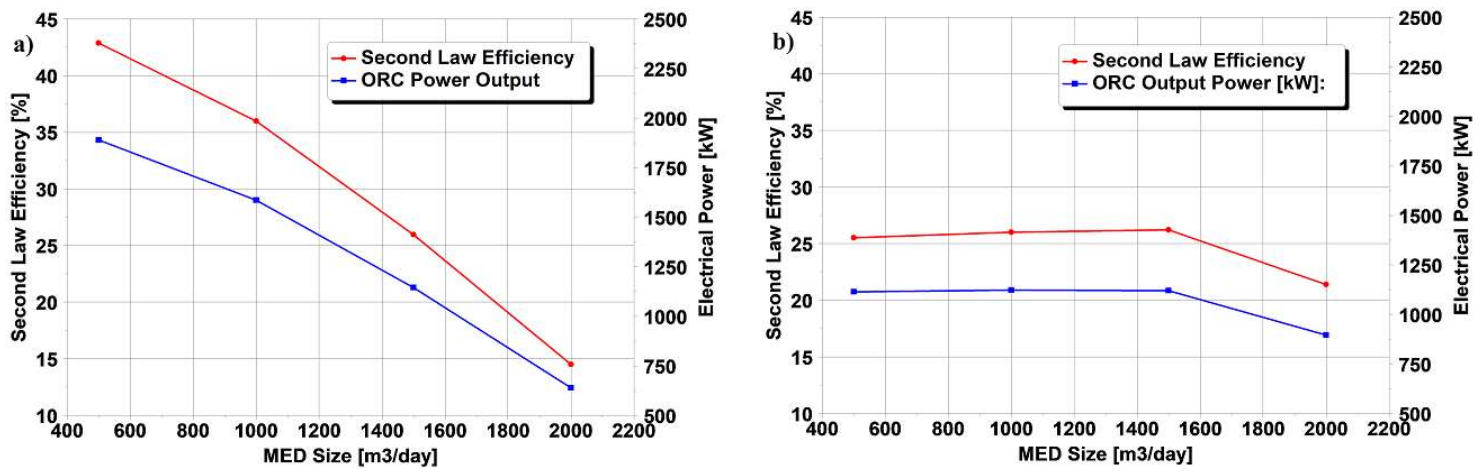

Figure 2. Second law efficiency and net power output for hybrid a) and cascade b) configuration.

It is worth to notice that the increase in the MED size involved a reduction of the ORC size, which cause a decrease of both the efficiency and the power output of the system in the case of hybrid configuration. This behaviour is due to the different amount of $\dot{W}_{N E T}$ and $\dot{W}_{\text {min }}$ : the minimum work of separation assumed very low values for thermal desalination processes as reported in the literature [31]. Indeed, the maximum second law efficiency of the system was led by the trend of the ORC power output. In the hybrid configuration, the growth of the MED caused a reduction of the amount of heat exchanged between the oil and the ORC and a consequent reduction of the power output of this latter.

With the hybrid configuration, the condensation temperature which maximized the system second law efficiency was $35^{\circ} \mathrm{C}$ for all the MED sizes: this means that both the preheater and the condenser were necessary to obtain a low condensing temperature and therefore a better cycle efficiency. In fact, the preheater exchanged just a part of the sensible heat of the organic fluid from the exchanger outlet and was unable to complete the condensation of the organic 
fluid due to the presence of the pinch-point. The ratio between the heat exchanged in the preheater and the global heat requested by the MED is reported in fig. 3.

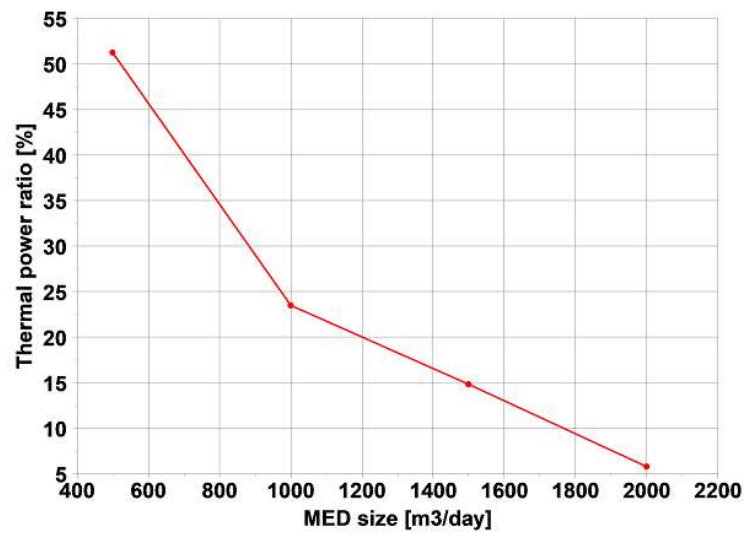

Figure 3. Ratio between the heat exchanged byin the preheater and the total heat requested by the MED for the hybrid configuration.

At optimal thermodynamic conditions the heat exchanged in the preheater is almost the $55 \%$ of the total heat requested by the process for a MED size of $500 \mathrm{~m}^{3} / \mathrm{h}$ and decreased up to the $6 \%$ for a MED size of $2000 \mathrm{~m}^{3} /$ day.

In the case of cascade configuration, instead, the maximum exergy efficiency slightly increased with the MED size, up to a maximum value, and sharply decreased at large MED size. In fact the heat exchanged with the oil in the evaporator increased with the size of the MED (as from fig. $4 \mathrm{~b}$, where the oil outlet temperature decreased with the MED size), due to the higher demand of heat of the system: for this reason, the evaporating pressure of the ORC decreased and the mass flow rate of working fluid increased, keeping almost constant the cycle power output (the growth of the second law efficiency is justified by the increase of the distillate water mass flow and therefore of $\left.\dot{W}_{\min }\right)$. The amount of heat requested in the first stage of the MED was proportional to the MED size and therefore the quality of the organic vapour at the outlet of the $1^{\text {st }}$ MED evaporator tended to reduce with the MED size. When the MED became large (more than $1500 \mathrm{~m}^{3} /$ day), the organic fluid totally condensed in the first MED evaporator, obliging the ORC to adapt itself to strictly follow the heat requested by the MED (and therefore 
dissipated by the condenser). This is the cause of the sharp reduction of power output and second law efficiency even in the optimal thermodynamic conditions when the size of the MED was larger than $1500 \mathrm{~m}^{3} /$ day. Regarding the condensing process, in the thermodynamic optimization and for all the size of the $\mathrm{MED}, 75^{\circ} \mathrm{C}$ was the temperature which maximized the system efficiency.

Comparing the two systems, it is clear that the hybrid configuration maximized the efficiency of the system for small MED sizes, while the cascade configuration seemed to be more suitable for larger MED, from a thermodynamic point of view.
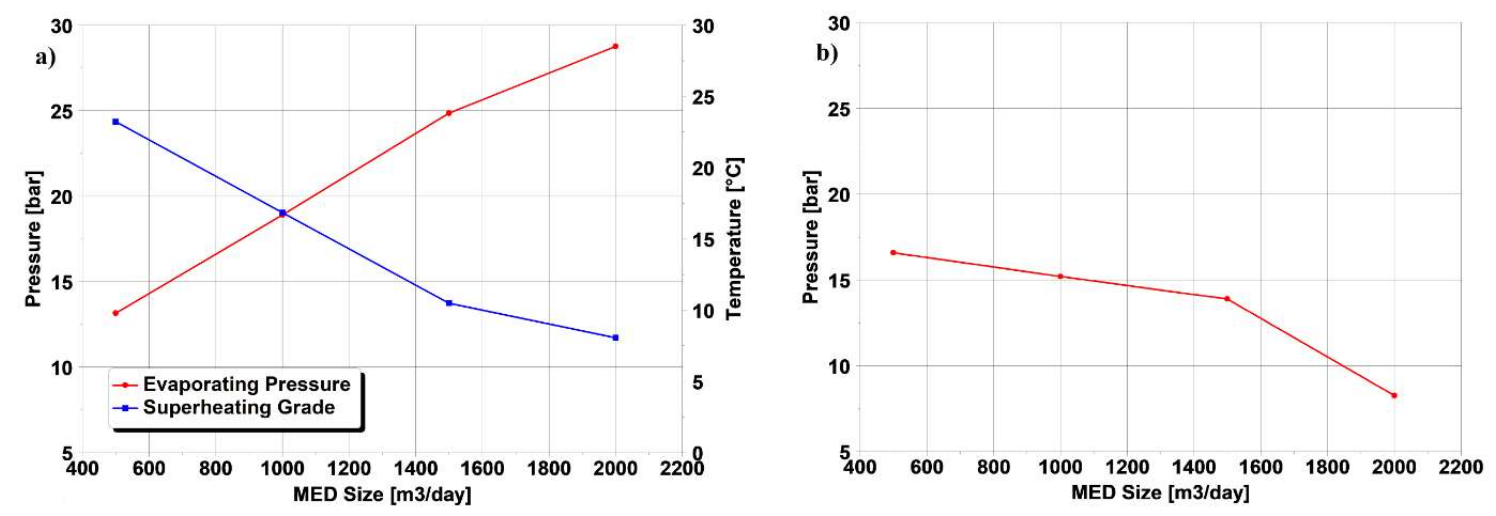

Figure 4. Evaporating pressure and superheating of the ORC for the hybrid a) and cascade configuration b).

For the hybrid configuration, the evaporating pressure (fig. 4) of the ORC increased with the MED size due to the increase of the HTF discharge temperature from the ORC evaporator, to provide the heat necessary to the MED (fig. 3). Due to the constraint of the heat to be provided to the MED, and therefore of the temperature at the ORC evaporator outlet, the increase in the evaporating pressure allowed the system to operate with the best possible match between the heat exchange curve, reducing entropy production and to operate with a high cycle efficiency. The optimal superheating grade (fig. 4a) was found to be decreasing with the size of the MED: at small MED size this condition resulted in a high temperature at the expander outlet to recover as much heat as possible in the preheater. 
In the case of the cascade configuration, instead, the optimal evaporating pressure decreased with the MED size: in fact, all the heat required by the system was transferred in the ORC evaporator and a reduction in the evaporating pressure resulted in a lower oil temperature at the evaporator outlet and therefore in a larger amount of heat exchanged. The sharp reduction of the pressure for large size of the MED ( $>1500 \mathrm{~m}^{3} /$ day) was due to the need for the complete condensation of the organic fluid in the MED evaporator and therefore in the necessity of the ORC to follow the heat rejected by the condenser. Regarding the fluid conditions at the inlet of the expander, the optimal solution was a cycle without superheating, for all the MED sizes and in fact, no entries about the optimal superheating grade are reported in fig. $4 \mathrm{~b}$. This happens because the optimal asset is reached when the power output is maximized and for a fixed exchanged heat, this condition is represented by a non-superheated cycle.
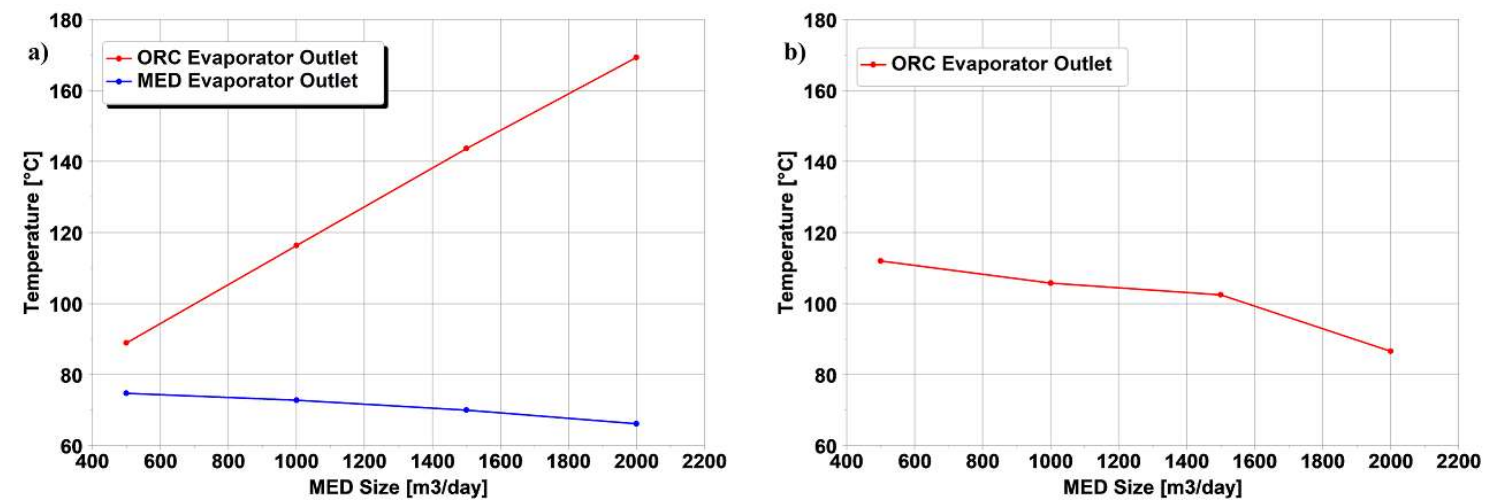

Figure 5: Oil temperature at the evaporator outlet of both ORC and MED for hybrid configuration a) and temperature at the outlet of the ORC evaporator for the cascade configuration b).

As regard of the outlet temperature of the oil, different results were obtained with the two architectures:

- for the hybrid configuration, the temperature of the oil discharged by the ORC evaporator (fig. 5) increased with the size of the MED, due to the larger amount of heat 
necessary to the desalination process. The outlet temperature of the HTF at the MED evaporator outlet (fig. 5) instead decreased with the size of the MED: this behaviour is due to the reduction of the heat exchanged in the preheater (fig. 3 ) and to the larger amount of heat globally requested by the system;

- in the case of the cascade configuration, the temperature of the oil at the ORC evaporator decreased almost linearly up to the MED size of $1500 \mathrm{~m}^{3} /$ day and then sharply decreased due to the complete condensation of the ORC working fluid in the MED evaporator.

The values of temperature, pressure, mass flow rate and exergy destruction and loss in the various components of the system were reported in the appendix for the thermodynamically optimized cases.

\subsection{Economic Analysis}

The economic analysis was carried out by comparing the investigated architectures with a baseline, conventional case, which is represented by a simple standalone MED cycle.

At first, the profitability index was evaluated for the baseline case, (fig. 6).

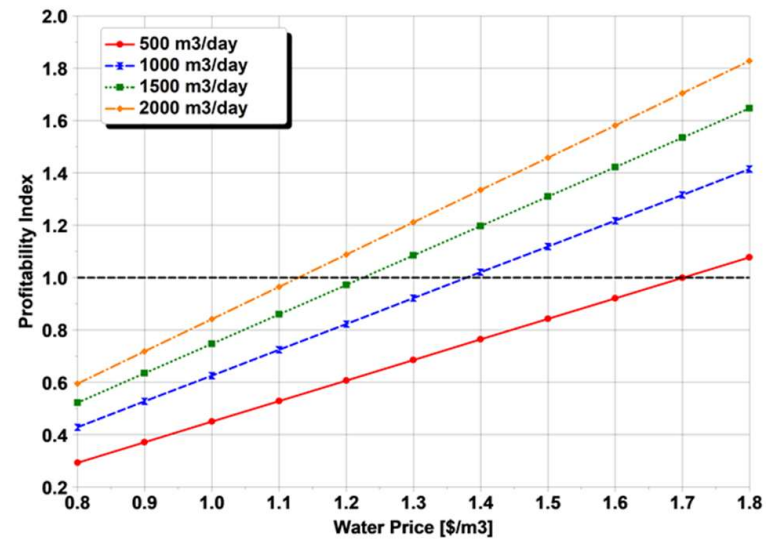

Figure 6. Investment profitability index with only the MED as recovery system. 
As from fig. 6, in a WHR context, the use of the MED as single recovery system is highly uneconomic for $500 \mathrm{~m}^{3} /$ day size for almost every water price. For higher values of the MED size, instead, the investment became feasible but for values of the water prices higher than 1.13 $\$ / \mathrm{m}^{3}\left(2000 \mathrm{~m}^{3} /\right.$ day). Acceptable values of the profitability index are however achieved with large systems and with a minimum water price of $1.4-1.5 \$ / \mathrm{m}^{3}$.

The economic analysis of the combined system (ORC and MED) was carried out by evaluating the profitability index and the payback time (PBT) of the investment for different electricity and water prices. The maximization of the profitability index was obtained by varying the evaporating pressure, superheating and condensing pressure for both the two configurations.;

\subsubsection{Hybrid configuration}

For the hybrid configuration, organic fluid temperature at the outlet of the preheater and HTF exhaust temperature at the $\mathrm{ORC}$ evaporator outlet were also considered as variables. For cascade configuration, the quality of the vapour of the working fluid at the outlet of the MED evaporator was added to the variables list. The profitability index and the payback time obtained by combining the MED with the ORC module are reported in fig. 7 and 8 for different values of the water and electricity prices and for different MED sizes in the case of hybrid configuration. 

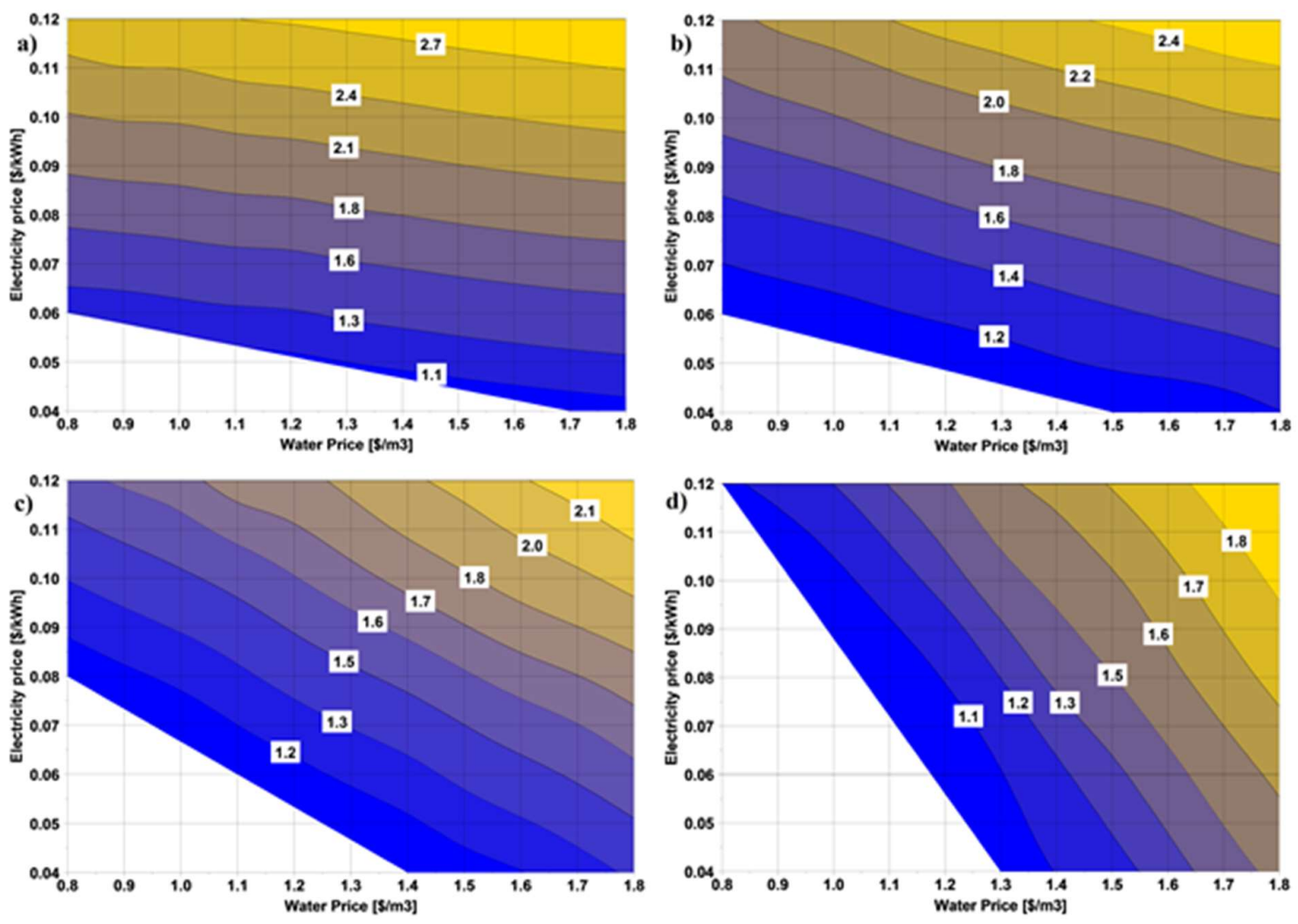

Fig. 7: Profitability index for different MED sizes: $500 \mathrm{~m}^{3} /$ day (A), $1000 \mathrm{~m}^{3} /$ day (B), 1500 $\mathrm{m}^{3} /$ day $(C)$ and $2000 \mathrm{~m}^{3} /$ day (D) for serial configuration.

As from fig. 7, the profitability index of the integrated system is often much higher than that of the MED alone (fig. 6), especially at the smallest MED sizes. For a MED size of $500 \mathrm{~m}^{3} / \mathrm{day}$, the investment resulted to be feasible also for low prices of electric energy and water. If the size of the MED is increased, however, due to the lower power output of the ORC, higher water and electricity prices were needed to reduce the payback time and increase the profitability index. The ratio between the profitability index of the integrated system and the one of the baseline case was always greater than the unit, except in the case of low electricity price and high water price for large MED sizes. The red line of fig. 9 represents the limit of convenience of the MEDORC integrated system with respect to the baseline. This means that the integration could improve the investment return with the exception of rare cases in almost all conditions, with the exception of rare cases. The largest gains respect to the baseline solution were achieved for 
small size of the MED $\left(500 \mathrm{~m}^{3} / \mathrm{h}\right)$. Regarding the configuration of the system, it is worth to notice that in all the cases, even with different electricity and water prices, the solver determined that the optimal preheater an exchange area was zero: in other words, this means that the hybrid configuration is not the optimal configuration for this integrated system, which is instead represented by a simpler serial configuration. The optimal configuration was therefore obtained by excluding the preheater. This result can be explained by the large exchange area needed due to the low exchange coefficient of the superheated vapour and in the high cost of the material involved in the construction: like for the condenser and MED exchangers, the preheater are is crossed by seawater with a high corrosive potential. In addition, while the preheater efficiency generally increases with superheating, the optimal superheating grade resulted to be very small from the economic analysis, with a reduction of the preheater efficiency. The replacement of the preheater with an internal heat exchanger might increase the net-work output especially for large size of the MED, when the discharge temperature of the HTF at the outlet of the evaporator is high. Indeed, from an economical point of view the optimal configuration is reduced to a simpler serial configuration. 

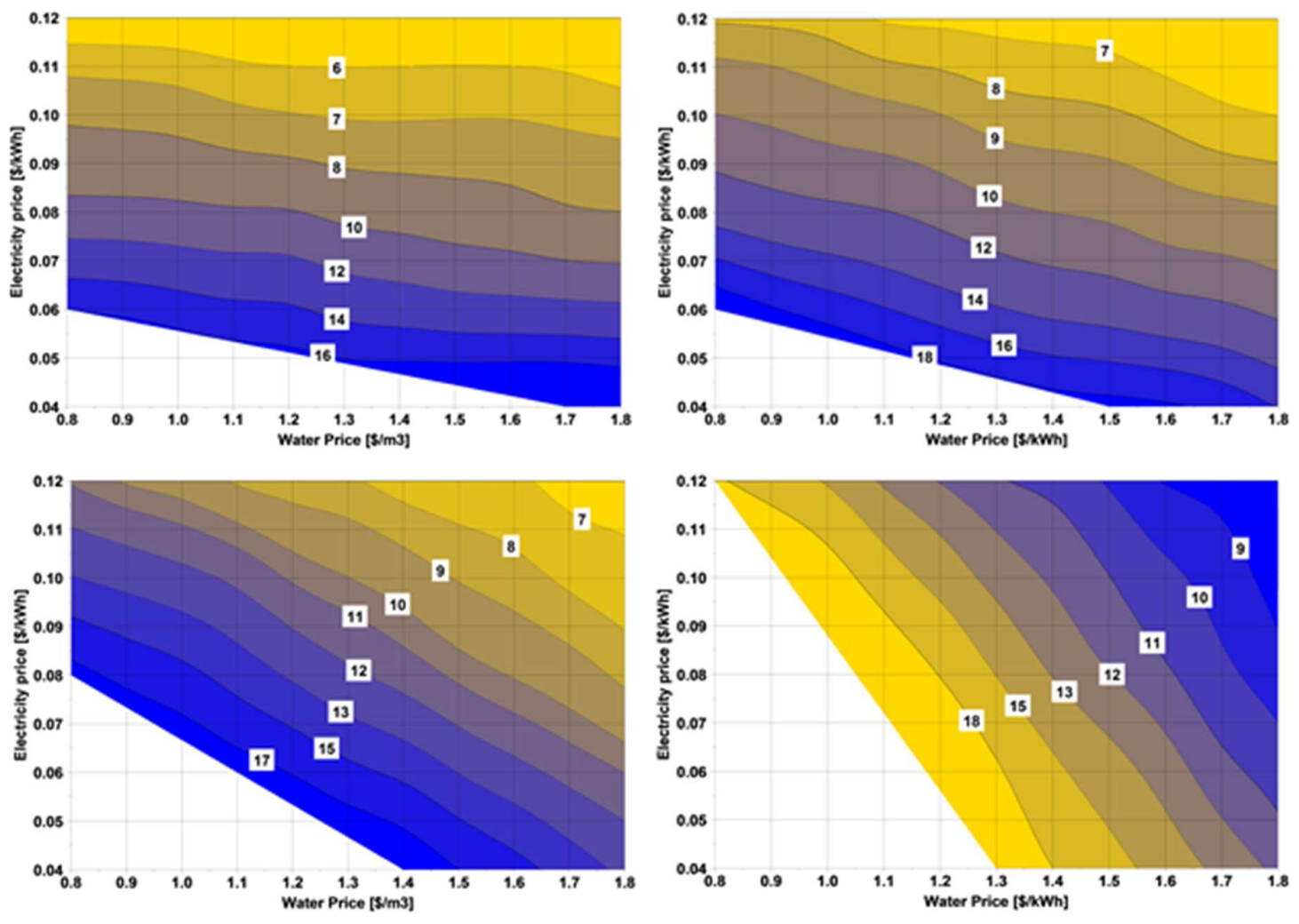

Figure 8. Payback Time for different MED sizes for serial configuration: $500 \mathrm{~m}^{3} /$ day (A), $1000 \mathrm{~m}^{3} /$ day (B), $1500 \mathrm{~m}^{3} /$ day (C) and $2000 \mathrm{~m}^{3} /$ day (D). 

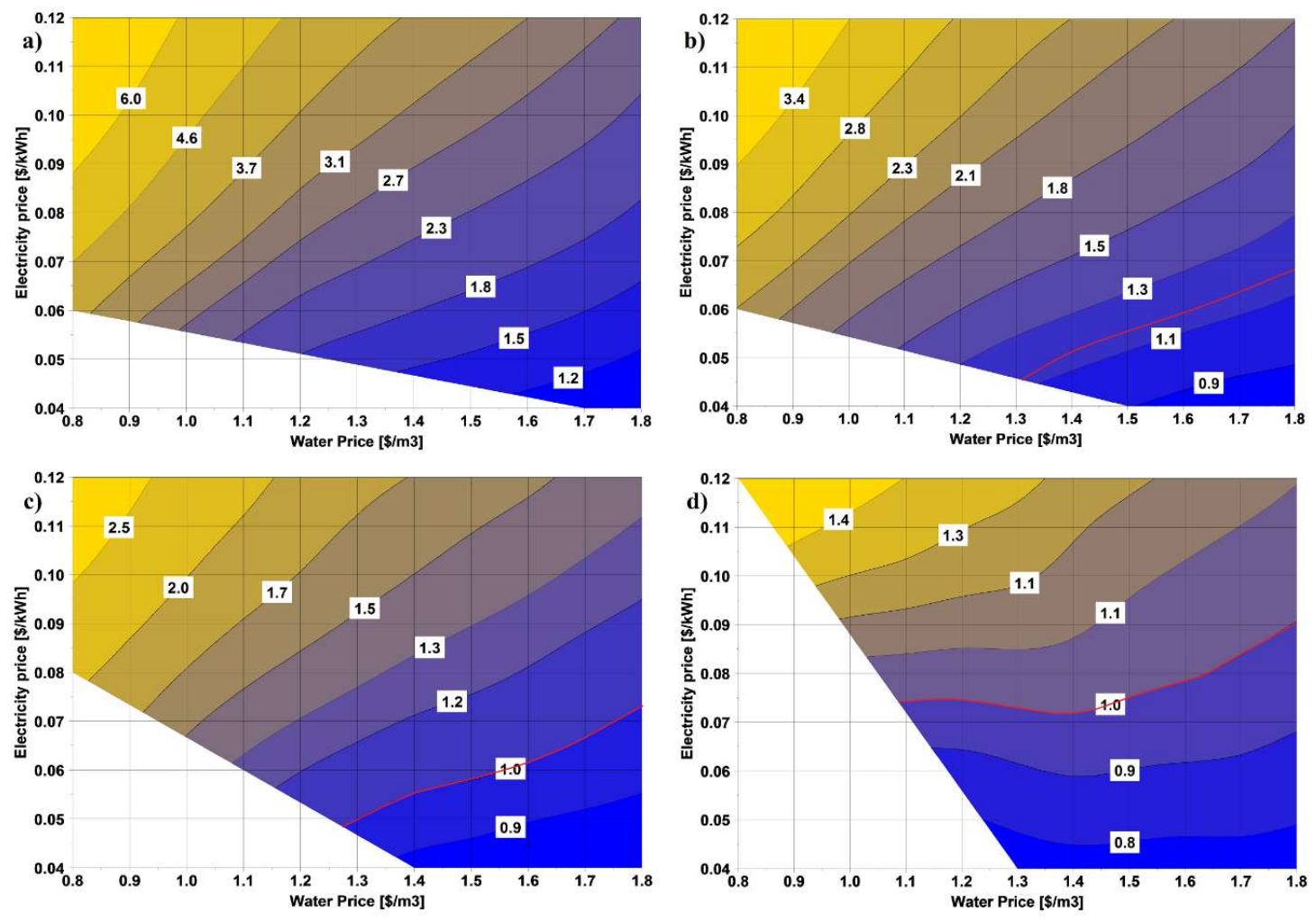

Figure 9. Ratio between the profitability index of the integrated system and profitability index of the only MED: $500 \mathrm{~m}^{3} /$ day (A), $1000 \mathrm{~m}^{3} /$ day (B), $1500 \mathrm{~m}^{3} /$ day (C) and $2000 \mathrm{~m}^{3} /$ day (D).

The red line represents the limit of convenience of the hybrid configuration respect to the baseline.

\subsubsection{Cascade Configuration}

Similarly to the hybrid configuration, the profitability index was calculated also for the cascade configuration, for various MED sizes (fig. 10). It is worth to notice that the profitability of this configuration is much lower than that of the serial configuration, due to the lower efficiency of the ORC unit and therefore to the higher equipment cost. For the MED size of $2000 \mathrm{~m}^{3} / \mathrm{h}$ the optimizer did not even lead to any profitable solution, due to the very low cycle efficiency, which was due to the extremely small pressure ratio under which the ORC unit was forced to operate. In this configuration, the optimizer converged to the absurd solution in which the 
evaporating and condensing temperature of the ORC were the same, and the power output was zero. Any other solution involving the generation of electrical power led to a less profitable result. As already stated, this configuration was hindered by the necessity of exchanging a large amount of heat through the condenser of the ORC, thus making the evaporator and the condenser largely oversized in comparison to the serial configuration. Indeed, the PBT was in every cases much higher than the serial configuration and, for the sake of brevity, it is not reported here.

As a whole, for the exploitation of waste heat at medium temperature, the economic analysis pointed out that the best architecture is therefore the serial configuration.
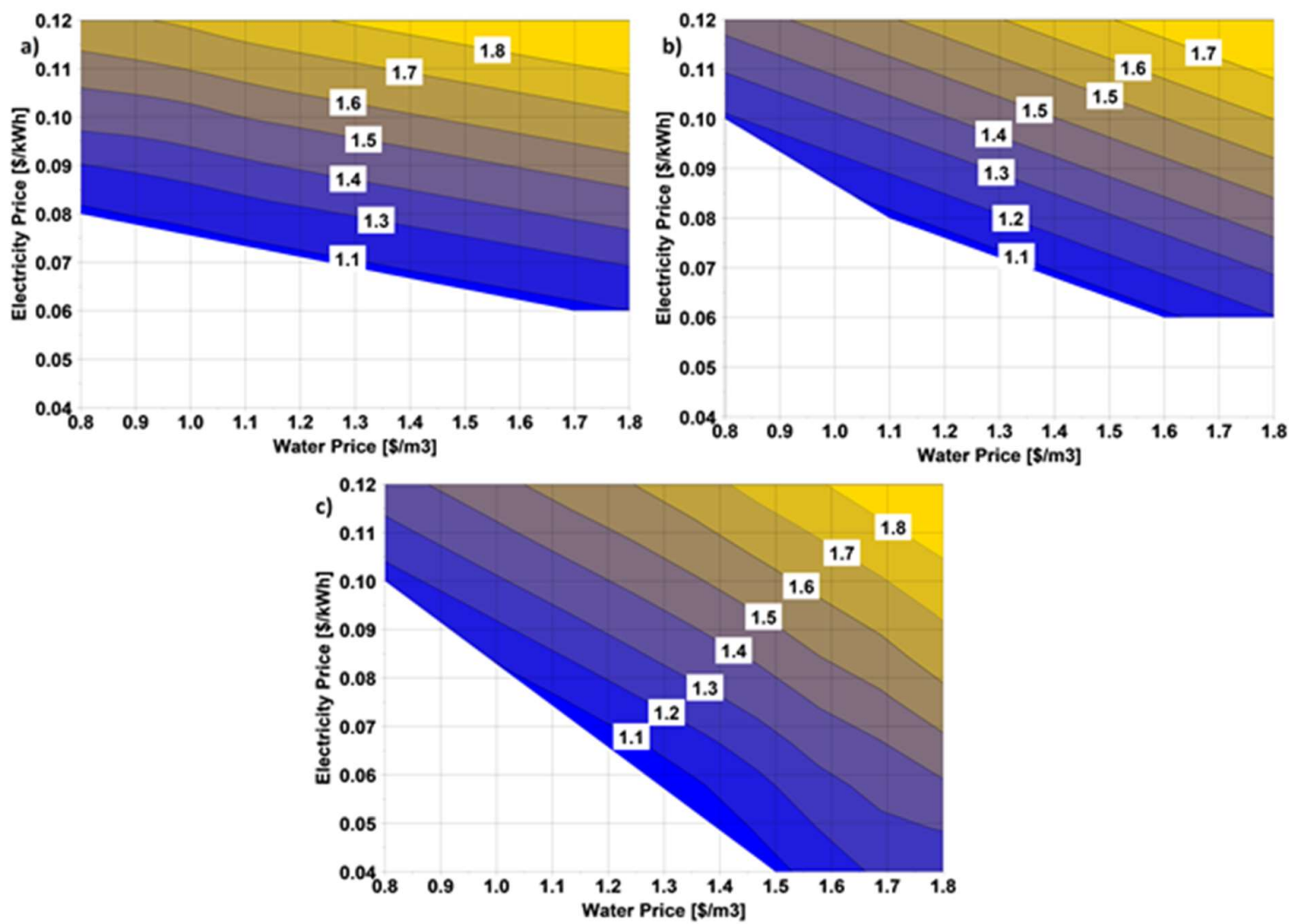

Fig. 10: Profitability index for the cascade configuration. a) $500 \mathrm{~m}^{3} /$ day, b) $1000 \mathrm{~m}^{3} /$ day, c) $1500 \mathrm{~m}^{3} / \mathrm{day}$. 


\subsubsection{General discussion}
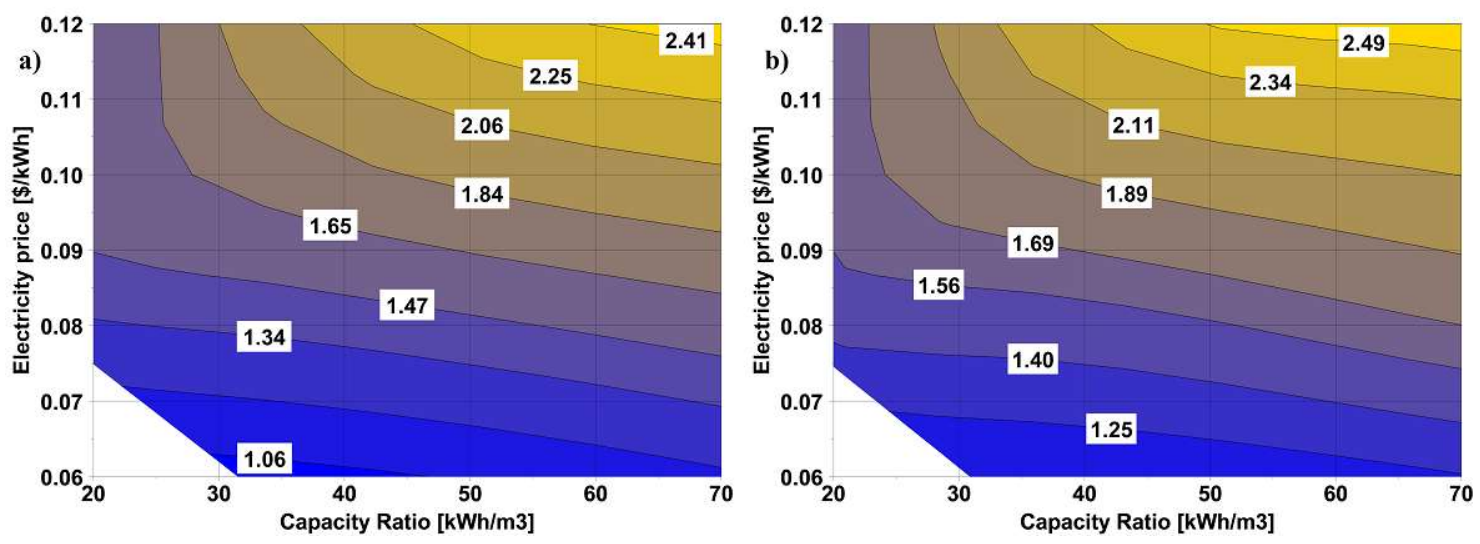

Figure 11: Profitability index as a function of the Capacity Ratio and of the electricity price for a water price of $0.8 \$ / m 3$ (left) and of $1 \$ / m 3$ (right) (serial configuration).

To extend the results of the analysis a new variable called capacity ratio has been introduced: this variable is defined as the ratio between the electric energy produced in a day and the water amount produced in a day:

$$
C_{R}=\frac{E_{e}}{V}
$$

This variable decreased with the size of the MED. For the serial configuration, with a fixed water price $\left(0.8\right.$ and $1 \$ / \mathrm{m}^{3}$, fig. 11$)$, the profitability index increased with the capacity ratio. Obviously, the largest increase was obtained for high electricity price. At low capacity ratio values, both for a water price of 0.8 and $1 \$ / \mathrm{m}^{3}$, the profitability index tended to increase slightly for low electricity prices and practically became constant for higher prices. For these values of the capacity ratio, in fact, the power output of the ORC is low and the increase of the electricity price has a minimum influence on the profitability index. For electricity price ranging between 0.09 and $0.12 \$ / \mathrm{kWh}$, and for water price in the range between 0.8 and $1 \$ / \mathrm{m}^{3}$, these results suggested that the ORC-MED integrated system should be designed with a capacity ratio higher than $45 \mathrm{kWh} / \mathrm{m}^{3} /$ day; to achieve a profitability index. 
Concluding, the serial solution proved to increase both the thermodynamic and economic performance of the MED, allowing a reduction of the water price.5 CONCLUSION

In this work, the coupling between an ORC and a MED, has been analysed from the thermodynamic and economic point of view for the case of a fixed waste heat power availability ease (20 MW in the present work). Two different configurations have been analysed: a hybrid serial-cascade and a cascade configuration.

The thermodynamic analysis showed that the ORC improved the second law efficiency of the system especially when the size of the MED was very small, due to the low value of the minimum work requested to separate salt and water. In addition, in most of the cases the hybrid configuration has a better second law efficiency than the cascade configuration. The economic analysis highlighted that the MED alone is uneconomic as a WHR system, especially for small the smallest sizes. The economic optimization reduced the hybrid configuration to a simpler serial configuration due to the high cost of the preheater: this was, in fact, the configuration which maximized the profit of the system. The combination of the ORC and MED in a serial configuration, proved to greatly the profitability index for almost all the considered case: particularly in the case of small MED size (500-1000 $\mathrm{m}^{3} /$ day), the analysis showed that the investment was profitable alse even at low prices of both electricity and water. Generally, for low water prices $\left(0.8-1 \$ / \mathrm{m}^{3}\right)$, the system should be designed with a capacity ratio higher than $45 \mathrm{kWh} / \mathrm{m}^{3} /$ day to obtain good profits in the range of the investigated electricity price.

\section{Nomenclature}

$\dot{Q} \quad[\mathrm{~kW}] \quad$ Thermal Power

$\dot{m} \quad[\mathrm{~kg} / \mathrm{s}] \quad$ Mass Flow
Subscripts
av Available
exch Exchanged 


\begin{tabular}{|c|c|c|c|c|}
\hline$C_{p}$ & {$[\mathrm{~kJ} / \mathrm{kg} / \mathrm{K}]$} & Constant Pressure Specific & & \\
\hline & & Heat & & \\
\hline$T$ & {$[\mathrm{~K}]$} & Temperature & 0 & Reference state \\
\hline$\dot{W}$ & {$[\mathrm{~kW}]$} & Mechanical Power & $t$ & Turbine \\
\hline$e x$ & {$[\mathrm{~kJ} / \mathrm{kg}]$} & Specific Exergy & $f . p$. & Feed Pump \\
\hline$C$ & {$[\$]$} & Cost & $p$ & Pump \\
\hline$V$ & - & Capacity & $d$ & Distillate Water \\
\hline$N P V$ & {$[\$]$} & Net Present Value & $s w$ & Sea Water \\
\hline$P$ & {$[\$]$} & Revenue & $H T F$ & High Temperature Fluid \\
\hline$i$ & - & Discount rate & gen & Electric generator \\
\hline$P I$ & - & Profitability index & $w$ & Water \\
\hline$P B T$ & [Years] & Payback time & & \\
\hline$C_{R}$ & {$\left[\mathrm{kWh} / \mathrm{m}^{3}\right]$} & Capacity Ratio & $e$ & Electricity \\
\hline$E$ & {$[\mathrm{kWh}]$} & Energy & $s$ & sensible \\
\hline$h$ & {$[\mathrm{~kJ} / \mathrm{kg}]$} & Enthalpy & $l$ & latent \\
\hline$S$ & {$[\mathrm{ppm}]$} & Salinity & $b$ & brine \\
\hline$A$ & & Size Parameter & & \\
\hline$U$ & $10 \mathrm{~W} / \mathrm{m}^{2} / \mathrm{U}$ & Overall Heat Transfer & & \\
\hline & & Coefficient & & \\
\hline WHR & & Waste Heat Recovery & & \\
\hline Greeks & & & $d$ & distillate \\
\hline$\eta$ & - & Efficiency & el & electric \\
\hline$\varepsilon$ & & Recovery Efficiency & & \\
\hline$\eta^{I I}$ & & Second Law Efficeincy & & \\
\hline
\end{tabular}


variation

$\rho \quad\left[\mathrm{kg} / \mathrm{m}^{3}\right] \quad$ density 


\section{Appendix}

In the appendix the thermodynamic state of the system at optimal thermodynamic conditions, for both the two configurations and for the various MED size analyzed in the studyare reported.

Exergy destruction and loss for each component of the system are also reported. For the sake of brevity, since the MED thermodynamic characteristics are constant (with the exception of the mass flow rate), a single value of exergy destruction was reported. This value takes into account the exergy destruction downstream to the first MED evaporator and preheater. In appendic C, a bar chart reporting the summary of exergy destruction and loss for the two configurations and for the various MED size is reported.

Appendix A1. Thermodynamic values of the system (Hybrid configuration, MED size $=500 \mathrm{~m}^{3} / \mathrm{day}$, thermodynamic optimization.

Table A1.1: System thermodynamic parameters

\begin{tabular}{lllll}
\hline Point & Fluid & $\begin{array}{l}\text { Temperature } \\
{\left[{ }^{\circ} \mathbf{C}\right]}\end{array}$ & $\begin{array}{l}\text { Pressure } \\
{[\text { bar }]}\end{array}$ & $\begin{array}{l}\text { Mass Flow Rate } \\
{[\mathbf{k g} / \mathbf{s}]}\end{array}$ \\
\hline B & Therminol VP-1 & 200.0 & 8.0 & 61.6 \\
C & Therminol VP-1 & 88.9 & 7.9 & 61.6 \\
D & Therminol VP-1 & 74.7 & 7.8 & 61.6 \\
1 & R601 & 35.71 & 13.2 & 22.5 \\
2 & R601 & 162.6 & 13.1 & 22.5 \\
3 & R601 & 104.3 & 1.1 & 22.5 \\
4 & R601 & 69.0 & 1.1 & 22.5 \\
5 & R601 & 35.0 & 1.0 & 22.5 \\
I MED Stage & Sea-water & 70.0 & 0.31 & - \\
II MED Stage & Sea-water & 62.9 & 0.22 & - \\
III MED Stage & Sea-water & 55.4 & 0.16 & - \\
IV MED Stage & Sea-water & 47.9 & 0.11 & - \\
V MED Stage & Sea-water & 40.4 & 0.07 & - \\
\hline
\end{tabular}

Table A1.2: Exergy destruction and losses

\begin{tabular}{ll}
\hline Component & I [kW] \\
\hline ORC Evaporator & 643 \\
ORC Turbine & 288 \\
MED Preheater & 103 \\
$1^{\text {st }}$ MED Evaporator & 23 \\
ORC Condenser & 529 \\
ORC Pump & 14 \\
MED & 410 \\
Oil out of the control volume & 496 \\
\hline
\end{tabular}


Appendix A2. Thermodynamic values of the system (Hybrid configuration, MED size $=1000 \mathrm{~m}^{3} / \mathrm{day}$, thermodynamic optimization.

Table A2.1: System thermodynamic parameters

\begin{tabular}{lllll}
\hline Point & Fluid & $\begin{array}{l}\text { Temperature } \\
{\left[{ }^{\circ} \mathrm{C}\right]}\end{array}$ & $\begin{array}{l}\text { Pressure } \\
{[\text { bar] }}\end{array}$ & $\begin{array}{l}\text { Mass Flow Rate } \\
{[\mathrm{kg} / \mathrm{s}]}\end{array}$ \\
\hline B & Therminol VP-1 & 200.0 & 8.0 & 61.6 \\
$\mathrm{C}$ & Therminol VP-1 & 116.3 & 7.9 & 61.6 \\
D & Therminol VP-1 & 72.8 & 7.8 & 61.6 \\
1 & R601 & 36.1 & 19.0 & 16.9 \\
2 & R601 & 176.9 & 18.9 & 16.9 \\
3 & R601 & 106.4 & 1.1 & 16.9 \\
4 & R601 & 63.0 & 1.1 & 16.9 \\
5 & R601 & 35.0 & 1.0 & 16.9 \\
I MED Stage & Sea-water & 70.0 & 0.31 & - \\
II MED Stage & Sea-water & 62.9 & 0.22 & - \\
III MED Stage & Sea-water & 55.4 & 0.16 & - \\
IV MED Stage & Sea-water & 47.9 & 0.11 & - \\
V MED Stage & Sea-water & 40.4 & 0.07 & - \\
\hline
\end{tabular}

Table A2.2: Exergy Destruction and Losses

\begin{tabular}{ll}
\hline Component & I [kW] \\
\hline ORC Evaporator & 554 \\
ORC Turbine & 244 \\
MED Preheater & 94 \\
$1^{\text {st }}$ MED Evaporator & 231 \\
ORC Condenser & 371 \\
ORC Pump & 16 \\
MED & 820 \\
Oil out of the control volume & 469 \\
\hline
\end{tabular}


Appendix A3. Thermodynamic values of the system (Hybrid configuration, MED size $=1500 \mathrm{~m}^{3} / \mathrm{day}$, thermodynamic optimization.

Table A3.1: System thermodynamic parameters

\begin{tabular}{lllll}
\hline Point & Fluid & $\begin{array}{l}\text { Temperature } \\
{\left[{ }^{\circ} \mathrm{C}\right]}\end{array}$ & $\begin{array}{l}\text { Pressure } \\
{[\text { bar] }}\end{array}$ & $\begin{array}{l}\text { Mass Flow Rate } \\
{[\mathrm{kg} / \mathrm{s}]}\end{array}$ \\
\hline B & Therminol VP-1 & 200.0 & 8.0 & 61.6 \\
$\mathrm{C}$ & Therminol VP-1 & 142.6 & 7.9 & 61.6 \\
D & Therminol VP-1 & 70.2 & 7.8 & 61.6 \\
1 & R601 & 36.4 & 24.9 & 11.6 \\
2 & R601 & 187.4 & 24.8 & 11.6 \\
3 & R601 & 104.8 & 1.1 & 11.6 \\
4 & R601 & 43.4 & 1.1 & 11.6 \\
5 & R601 & 35.0 & 1.0 & 11.6 \\
I MED Stage & Sea-water & 70.0 & 0.31 & - \\
II MED Stage & Sea-water & 62.9 & 0.22 & - \\
III MED Stage & Sea-water & 55.4 & 0.16 & - \\
IV MED Stage & Sea-water & 47.9 & 0.11 & - \\
V MED Stage & Sea-water & 40.4 & 0.07 & - \\
\hline
\end{tabular}

Table A3.2: Exergy Destruction and Losses

\begin{tabular}{ll}
\hline Component & I [kW] \\
\hline ORC Evaporator & 468 \\
ORC Turbine & 187 \\
MED Preheater & 62 \\
$1^{\text {st }}$ MED Evaporator & 566 \\
ORC Condenser & 221 \\
ORC Pump & 15 \\
MED & 1278 \\
Oil out of the control volume & 430 \\
\hline
\end{tabular}


Appendix A4. Thermodynamic values of the system (Hybrid configuration, MED size $=2000 \mathrm{~m}^{3} / \mathrm{day}$, thermodynamic optimization.

Table A4.1: System thermodynamic parameters

\begin{tabular}{lllll}
\hline Point & Fluid & $\begin{array}{l}\text { Temperature } \\
{\left[{ }^{\circ} \mathrm{C}\right]}\end{array}$ & $\begin{array}{l}\text { Pressure } \\
{[\text { bar] }}\end{array}$ & $\begin{array}{l}\text { Mass Flow Rate } \\
{[\mathrm{kg} / \mathrm{s}]}\end{array}$ \\
\hline B & Therminol VP-1 & 200.0 & 8.0 & 61.6 \\
$\mathrm{C}$ & Therminol VP-1 & 142.6 & 7.9 & 61.6 \\
D & Therminol VP-1 & 70.2 & 7.8 & 61.6 \\
1 & R601 & 36.6 & 28.8 & 6.4 \\
2 & R601 & 194.3 & 28.7 & 6.4 \\
3 & R601 & 103.8 & 1.1 & 6.4 \\
4 & R601 & 46.4 & 1.1 & 6.4 \\
5 & R601 & 35 & 1.0 & 6.4 \\
I MED Stage & Sea-water & 70.0 & 0.31 & - \\
II MED Stage & Sea-water & 62.9 & 0.22 & - \\
III MED Stage & Sea-water & 55.4 & 0.16 & - \\
IV MED Stage & Sea-water & 47.9 & 0.11 & - \\
V MED Stage & Sea-water & 40.4 & 0.07 & - \\
\hline
\end{tabular}

Table A4.2: Exergy Destruction and Losses

\begin{tabular}{ll}
\hline Component & I [kW] \\
\hline ORC Evaporator & 313 \\
ORC Turbine & 103 \\
MED Preheater & 53 \\
$1^{\text {st }}$ MED Evaporator & 1127 \\
ORC Condenser & 120 \\
ORC Pump & 9 \\
MED & 1621 \\
Oil out of the control volume & 374 \\
\hline
\end{tabular}


Appendix B1. Thermodynamic values of the system (Cascade, MED size $=500 \mathrm{~m}^{3} / \mathrm{day}$, thermodynamic optimization).

Table B1.1: System thermodynamic parameters

\begin{tabular}{lllll}
\hline Point & Fluid & $\begin{array}{l}\text { Temperature } \\
{\left[{ }^{\circ} \mathbf{C}\right]}\end{array}$ & $\begin{array}{l}\text { Pressure } \\
{[\mathrm{bar}]}\end{array}$ & $\begin{array}{l}\text { Mass Flow Rate } \\
{[\mathrm{kg} / \mathrm{s}]}\end{array}$ \\
\hline B & Therminol VP-1 & 200.0 & 8.0 & 61.6 \\
$\mathrm{C}$ & Therminol VP-1 & 112.0 & 7.9 & 61.6 \\
1 & R601 & 76.1 & 16.7 & 24.0 \\
2 & R601 & 152.8 & 16.6 & 24.0 \\
3 & R601 & 107 & 3.3 & 24.0 \\
4 & R601 & 75.2 & 3.2 & 24.0 \\
5 & R601 & 75.2 & 3.2 & 24.0 \\
I MED Stage & Sea-water & 70.0 & 0.31 & - \\
II MED Stage & Sea-water & 62.9 & 0.22 & - \\
III MED Stage & Sea-water & 55.4 & 0.16 & - \\
IV MED Stage & Sea-water & 47.9 & 0.11 & - \\
V MED Stage & Sea-water & 40.4 & 0.07 & - \\
\hline
\end{tabular}

Table B1.2: Exergy Destruction and Losses

\begin{tabular}{ll}
\hline Component & I [kW] \\
\hline ORC Evaporator & 352 \\
ORC Turbine & 172 \\
$1^{\text {st }}$ MED Evaporator & 113 \\
ORC Condenser & 947 \\
ORC Pump & 16 \\
MED & 410 \\
Oil out of the control volume & 1272 \\
\hline
\end{tabular}


Appendix B2. Thermodynamic values of the system (Cascade, MED size $=1000 \mathrm{~m}^{3} /$ day, thermodynamic optimization.

Table B2.1: System thermodynamic parameters

\begin{tabular}{lllll}
\hline Point & Fluid & $\begin{array}{l}\text { Temperature } \\
{\left[{ }^{\circ} \mathbf{C}\right]}\end{array}$ & $\begin{array}{l}\text { Pressure } \\
{[\mathrm{bar}]}\end{array}$ & $\begin{array}{l}\text { Mass Flow Rate } \\
{[\mathrm{kg} / \mathrm{s}]}\end{array}$ \\
\hline B & Therminol VP-1 & 200.0 & 8.0 & 61.6 \\
$\mathrm{C}$ & Therminol VP-1 & 105.7 & 7.9 & 61.6 \\
1 & R601 & 76.0 & 15.1 & 26.1 \\
2 & R601 & 146.0 & 15.0 & 26.1 \\
3 & R601 & 104.8 & 3.3 & 26.1 \\
4 & R601 & 75.2 & 3.2 & 26.1 \\
5 & R601 & 75.2 & 3.2 & 26.1 \\
I MED Stage & Sea-water & 70.0 & 0.31 & - \\
II MED Stage & Sea-water & 62.9 & 0.22 & - \\
III MED Stage & Sea-water & 55.4 & 0.16 & - \\
IV MED Stage & Sea-water & 47.9 & 0.11 & - \\
V MED Stage & Sea-water & 40.4 & 0.07 & - \\
\hline
\end{tabular}

Table B2.2: Exergy Destruction and Losses

\begin{tabular}{ll}
\hline Component & $\mathbf{I}[\mathbf{k W}]$ \\
\hline ORC Evaporator & 390 \\
ORC Turbine & 174 \\
$1^{\text {st }}$ MED Evaporator & 155 \\
ORC Condenser & 582 \\
ORC Pump & 15 \\
MED & 820 \\
Oil out of the control volume & 1125 \\
\hline
\end{tabular}


Appendix B3. Thermodynamic values of the system (Cascade, MED size $=1500 \mathrm{~m}^{3} /$ day, thermodynamic optimization.

Table B.3.1: System thermodynamic parameters

\begin{tabular}{lllll}
\hline Point & Fluid & $\begin{array}{l}\text { Temperature } \\
{\left[{ }^{\circ} \mathrm{C}\right]}\end{array}$ & $\begin{array}{l}\text { Pressure } \\
{[\mathrm{bar}]}\end{array}$ & $\begin{array}{l}\text { Mass Flow Rate } \\
{[\mathrm{kg} / \mathrm{s}]}\end{array}$ \\
\hline B & Therminol VP-1 & 200.0 & 8.0 & 61.6 \\
$\mathrm{C}$ & Therminol VP-1 & 102.4 & 7.9 & 61.6 \\
1 & R601 & 75.9 & 14.0 & 27.2 \\
2 & R601 & 142.0 & 13.9 & 27.2 \\
3 & R601 & 103.4 & 3.3 & 27.2 \\
4 & R601 & 75.2 & 3.2 & 27.2 \\
5 & R601 & 75.2 & 3.2 & 27.2 \\
I MED Stage & Sea-water & 70.0 & 0.31 & - \\
II MED Stage & Sea-water & 62.9 & 0.22 & - \\
III MED Stage & Sea-water & 55.4 & 0.16 & - \\
IV MED Stage & Sea-water & 47.9 & 0.11 & - \\
V MED Stage & Sea-water & 40.4 & 0.07 & - \\
\hline
\end{tabular}

Table B3.2: Exergy Destruction and Losses

\begin{tabular}{ll}
\hline Component & I [kW] \\
\hline ORC Evaporator & 412 \\
ORC Turbine & 175 \\
$1^{\text {st } M E D ~ E v a p o r a t o r ~}$ & 198 \\
ORC Condenser & 128 \\
ORC Pump & 14 \\
MED & 1278 \\
Oil out of the control volume & 1048 \\
\hline
\end{tabular}


Appendix B4. Thermodynamic values of the system (Cascade, MED size $=2000 \mathrm{~m}^{3} /$ day, thermodynamic optimization.

\begin{tabular}{lllll}
\hline Point & Fluid & $\begin{array}{l}\text { Temperature } \\
{\left[{ }^{\circ} \mathbf{C}\right]}\end{array}$ & $\begin{array}{l}\text { Pressure } \\
{[\text { bar }]}\end{array}$ & $\begin{array}{l}\text { Mass Flow Rate } \\
{[\mathbf{k g} / \mathbf{s}]}\end{array}$ \\
\hline B & Therminol VP-1 & 200.0 & 8.0 & 61.6 \\
$\mathrm{C}$ & Therminol VP-1 & 86.6 & 7.9 & 61.6 \\
1 & R601 & 75.5 & 8.4 & 34.3 \\
2 & R601 & 115.5 & 8.2 & 34.3 \\
3 & R601 & 92.4 & 3.3 & 34.3 \\
4 & R601 & 75.2 & 3.2 & 34.3 \\
5 & R601 & - & - & - \\
I MED Stage & Sea-water & 70.0 & 0.31 & - \\
II MED Stage & Sea-water & 62.9 & 0.22 & - \\
III MED Stage & Sea-water & 55.4 & 0.16 & - \\
IV MED Stage & Sea-water & 47.9 & 0.11 & - \\
V MED Stage & Sea-water & 40.4 & 0.07 & - \\
\hline
\end{tabular}

TableB4.1: System thermodynamic parameters

Table B4.2: Exergy Destruction and Losses

\begin{tabular}{ll}
\hline Component & I [kW] \\
\hline ORC Evaporator & 737 \\
ORC Turbine & 143 \\
1 $^{\text {st } \text { MED Evaporator }}$ & 220 \\
ORC Condenser & - \\
ORC Pump & 9 \\
MED & 1621 \\
Oil out of the control volume & 712 \\
\hline
\end{tabular}




\section{Appendix C: analysis of the exergy destruction and loss}

For a better comprehension the value reported in the previous tables are reported in fig. XX for the hybrid (serial-cascade) configuration and for the cascade configuration.

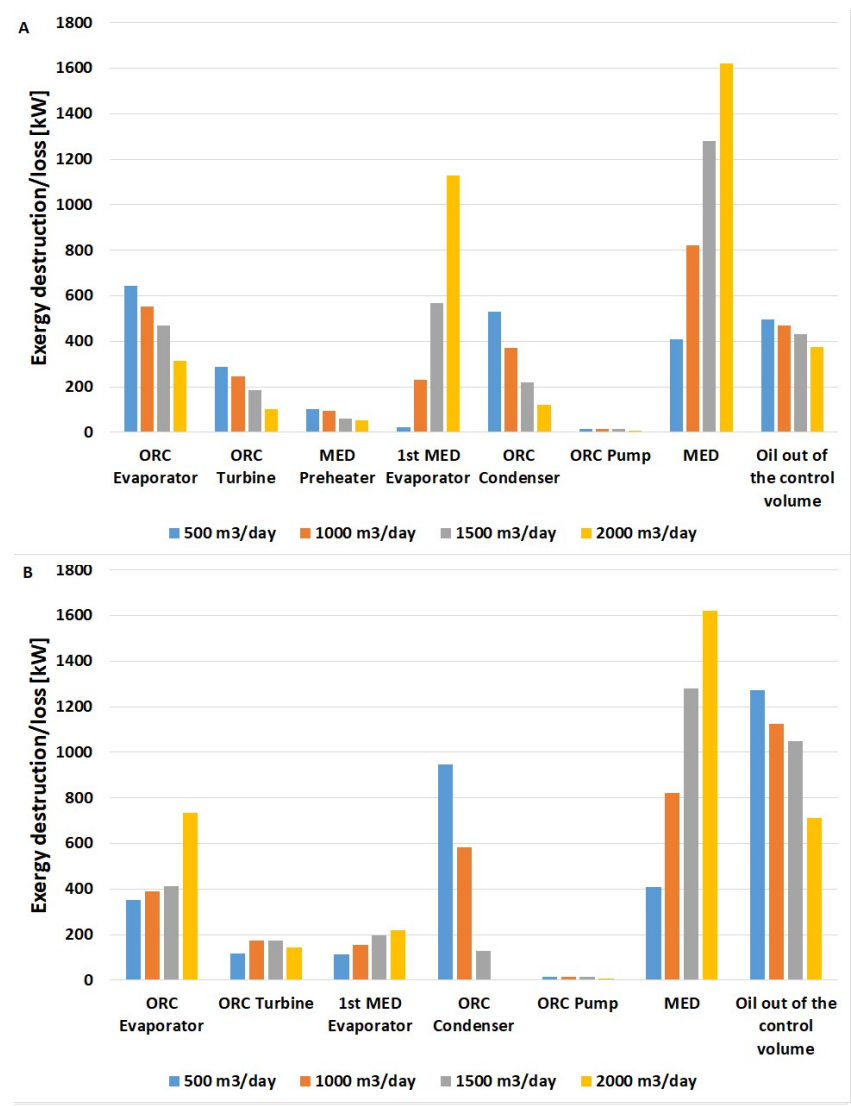

Fig. C1: Exergy destruction and losses of the system

Hybrid Serial cascade configuration:

- ORC Evaporator: The exergy destruction decreased due to increase of evaporating pressure and to the decrease of the ORC mass flow rate with the MED size;

- ORC Turbine: The trend is decreasing with the MED size, mainly due to the decrease of the mass flow rate;

- MED Preheater: The trend of exergy destruction is decreasing due to the lower heat exchanged in the device with the size;

- $\mathbf{1}^{\text {st }}$ MED evaporator: The trend of exergy destruction is increasing with the MED size, due to the largest amount of heat exchanged in this device and to the oil temperature increase at the ORC evaporator outlet (bad match between heat transfer curves);

- ORC condenser: The trend is decreasing, mainly due to the reduction of the working fluid mass flow rate in the ORC with the MED size;

- ORC pump: The destruction in the pump is very low and is decreasing with the MED size, due to the working fluid mass flow rate reduction;

- MED: The exergy destruction increased with its size;

- Exergy loss due to oil flowing out of the control volume: The exergy loss decreased with the MED size since the oil temperature decreased; 
Cascade Configuration:

- ORC Evaporator: The exergy destruction in this component increased with the size of the MED mainly due to the reduction of the evaporating pressure (bad match between heat transfer curves) and to the increase of the ORC mass flow rate;

- ORC turbine: the trend present a maximum: in fact if from one hand the reduction of the pressure ratio reduces the exergy destruction, from the other the mass flow increase tend to increase the destruction of exergy in this device;

- $1^{\text {st }}$ MED evaporator: Exergy destruction increased due to higher amount of heat exchanged with the MED size;

- ORC condenser: The exergy destruction decreased with MED size because the largest part of the heat of condensation was transferred in the $1^{\text {st }}$ MED evaporator. With a MED size $\mathrm{m}^{3} / \mathrm{day}$ this component was not present since all the condensation occurred in the $1^{\text {st }}$ MED evaporator.

- ORC pump: The exergy destruction in the ORC pump was decreasing with MED size due to the reduction of the pressure evaporating pressure (and therefore of the pressure ratio) of the ORC;

- MED: The exergy destruction increased with its size;

- Exergy loss due to oil flowing out of the control volume: The exergy loss associated to the outflow of the oil from the control volume decreased with the MED size, due to the reduction of the oil temperature after ORC evaporator.

\section{REFERENCES}

[1] Li, Y. Goswami, E. Stefanakos, Solar assisted sea water desalination: A review, Renewable And Sustainable Energy Reviews. 19 (2013) 136-163.

[2] T. Mezher, H. Fath, Z. Abbas, A. Khaled, Techno-economic assessment and environmental impacts of desalination technologies, Desalination. 266 (2011) 263-273.

[3] M. Sharaf, A. Nafey, L. García-Rodríguez, Thermo-economic analysis of solar thermal power cycles assisted MED-VC (multi effect distillation-vapor compression) desalination processes, Energy. 36 (2011) 2753-2764

[4] D. Maraver, J. Uche, J. Royo, Assessment of high temperature organic Rankine cycle engine for polygeneration with MED desalination: A preliminary approach, Energy Conversion And Management. 53 (2012) 108-117.

[5] M. Sharaf, Thermo-Economic Comparisons of Different Types of Solar Desalination Processes, Journal Of Solar Energy Engineering. 134 (2012) 031001. 
[6] O. Morin, Design and operating comparison of MSF and MED systems, Desalination. 93 (1993) 69-109.

[7] N. Wade, Distillation plant development and cost update, Desalination. 136 (2001) 312

[8] S. Ihm, O. Al-Najdi, O. Hamed, G. Jun, H. Chung, Energy cost comparison between MSF, MED and SWRO: Case studies for dual purpose plants, Desalination. 397 (2016) 116-125.

[9] S. Kalogirou, Survey of solar desalination systems and system selection, Energy. 22 (1997) 69-81.

[10] Al-Karaghouli, L. Kazmerski, Energy consumption and water production cost of conventional and renewable-energy-powered desalination processes, Renewable And Sustainable Energy Reviews. 24 (2013) 343-356.

[11] Desalination for safe water supply: guidance for the health and environmental aspects applicable to desalination, Public Health and the Environment World Health Organization, Geneva 2007.

[12] M. Darwish, H. Abdulrahim, A. Mabrouk, A. Hassan, Cogeneration Power-Desalting Plants Using Gas Turbine Combined Cycle, Desalination Updates. (2015).

[13] A. Almutairi, P. Pilidis, N. Al-Mutawa, M. Al-Weshahi, Energetic and exergetic analysis of cogeneration power combined cycle and ME-TVC-MED water desalination plant: Part-1 operation and performance, Applied Thermal Engineering. 103 (2016) 7791.

[14] A. Hanafi, G. Mostafa, A. Fathy, A. Waheed, Thermo-Economic Analysis of Combined Cycle MED-TVC Desalination System, Energy Procedia. 75 (2015) 1005-1020. 
[15] K. Maghsoudi, M. Aliasghari, A. Mehrpanahi, Thermoeconomic investigation of coupling MED-TVC with a combined cycle power plant, Desalination And Water Treatment. 57 (2015) 17707-17721.

[16] Rubio, J. Uche, N. Dejo, Optimization of desalted water production in a poligeneration scheme for the tourist sector, Desalination. 223 (2008) 464-475.

[17] L. Serra, M. Lozano, J. Ramos, A. Ensinas, S. Nebra, Polygeneration and efficient use of natural resources, Energy. 34 (2009) 575-586.

[18] K. Maheswari, K. Kalidasa Murugavel, G. Esakkimuthu, Thermal desalination using diesel engine exhaust waste heat — An experimental analysis, Desalination. 358 (2015) 94-100.

[19] Ibarra, A. Rovira, D. Alarcón-Padilla, G. Zaragoza, J. Blanco, Performance of a 5 kWe Solar-only Organic Rankine Unit Coupled to a Reverse Osmosis Plant, Energy Procedia. 49 (2014) 2251-2260.

[20] A. Araghi, M. Khiadani, K. Hooman, A novel vacuum discharge thermal energy combined desalination and power generation system utilizing R290/R600a, Energy. 98 (2016) 215-224.

[21] M. Sharaf, A. Nafey, L. García-Rodríguez, Exergy and thermo-economic analyses of a combined solar organic cycle with multi effect distillation (MED) desalination process, Desalination. 272 (2011) 135-147.

[22] M. Sharaf Eldean, A. Soliman, A novel study of using oil refinery plants waste gases for thermal desalination and electric power generation: Energy, exergy \& cost evaluations, Applied Energy. 195 (2017) 453-477.

[23] C. Wieland, D. Meinel, S. Eyerer, H. Spliethoff, Innovative CHP concept for ORC and its benefit compared to conventional concepts, Applied Energy. 183 (2016) 478-490. 
[24] A. Baccioli, M. Antonelli, U. Desideri, Technical and economic analysis of organic flash regenerative cycles (OFRCs) for low temperature waste heat recovery, Applied Energy. 199 (2017) 69-87. doi:10.1016/j.apenergy.2017.04.058.

[25] http://home.aspentech.com/en/products/engineering/aspen-hysys (Last access 09/02/2018).

[26] B. Maha, S. Ali, B. Ammar, Modeling and simulation of multi-effect desalination plant (SIDEM unit), 2017 International Conference On Green Energy Conversion Systems (GECS). (2017).

[27] C. Chen, Representation of solid-liquid equilibrium of aqueous electrolyte systems with the electrolyte NRTL model, Fluid Phase Equilibria. 27 (1986) 457-474.

[28] W. A. S. Moon and M. Lee, "Energy Consumption in Forward Osmosis Desalination Compared to other Desalination Techniques,” 2012.

[29] H. El-Dessouky, H. Ettouney, Fundamentals of salt water desalination, 1st ed., Elsevier, Amsterdam, 2002.

[30] Therminol VP1 Datasheet https://www.therminol.com/products/Therminol-VP1 (last access 04/06/2018)

[31] N. Kahraman, Y. Cengel, Exergy analysis of a MSF distillation plant, Energy Conversion And Management. 46 (2005) 2625-2636.

[32] Turton, R.; Bailie, R.C.; Whiting, W.B.; Shaeiwitz, J.A.; Bhattacharyya, D. Analysis, Synthesis, and Design of Chemical Processes, 4th ed.; Pearson Education International: Upper Saddle River, NJ, USA, 2013.

[33] R.K. Sinnott, Chemical Engineering Design, SI ed., Elsevier, 2009.

[34] A. Benato, Improving the efficiency of a cataphoresis oven with a cogenerative organic Rankine cycle unit, Thermal Science And Engineering Progress. 5 (2017) 182-194. 
[35] S. Lemmens, Cost Engineering Techniques and Their Applicability for Cost Estimation of Organic Rankine Cycle Systems, Energies. 9 (2016) 485. 